\title{
Why does research in finance have so little impact?
}

Article

Accepted Version

Creative Commons: Attribution-Noncommercial-No Derivative Works 4.0

Brooks, C., Fenton, E., Schopohl, L. and Walker, J. (2019) Why does research in finance have so little impact? Critical Perspectives on Accounting, 58. pp. 24-52. ISSN 1045-2354 doi: https://doi.org/10.1016/j.cpa.2018.04.005 Available at https://centaur.reading.ac.uk/76975/

It is advisable to refer to the publisher's version if you intend to cite from the work. See Guidance on citing.

To link to this article DOI: http://dx.doi.org/10.1016/j.cpa.2018.04.005

Publisher: Elsevier

All outputs in CentAUR are protected by Intellectual Property Rights law, including copyright law. Copyright and IPR is retained by the creators or other copyright holders. Terms and conditions for use of this material are defined in the End User Agreement.

\section{www.reading.ac.uk/centaur}

\section{CentAUR}

Central Archive at the University of Reading

Reading's research outputs online 


\title{
Why does research in finance have so little impact?
}

\author{
Chris Brooks*, Evelyn Fenton, Lisa Schopohl, James Walker \\ Henley Business School, University of Reading.
}

\begin{abstract}
The quantity of finance research has grown enormously over the past two decades, yet questions remain over its breadth and ability to benefit the economy and society beyond academia. Using multisource data, we argue that individual and institutional incentives have fostered insularity and a consequent homogeneity in the discipline. We examine the characteristics of research that is published and cited in the leading field journals in finance, arguing that the work has become abstract and unrelated to real world issues. The work published in the 'top' journals makes increasing use of US data, even where the researchers are drawn from different countries. Using information from impact assessment, publication patterns, and grant capture, we illustrate that this narrow agenda lacks relevance to the financial services sector, the economy or wider society compared to other areas of business and management research. In particular, we highlight the relative absence of research on ethics in academic finance and discuss the likely consequences for the discipline including its relevance to society.
\end{abstract}

Keywords: critical finance; journal ratings lists; impact; elitism in publishing; incentive structures; ethical finance research.

JEL Classifications: A11, B41, O30

* Chris Brooks (corresponding author), ICMA Centre, Henley Business School, University of Reading, Whiteknights, Reading RG6 6BA, UK; tel: (+44) 118 3787809; fax: (+44) 11893131 4741; e-mail: C.Brooks@,reading.ac.uk 


\section{Introduction}

Research in universities is increasingly required to demonstrate impact for the society which funds it. In the UK, this focus has led to the setting up of research assessment systems to ensure that academics account for the impact of their research on non-academics (Geuna \& Martin, 2003; Hicks, 2012; Bornmann, 2013). Business School scholarship would seem ideally placed to make substantive contributions to organisations and the economy. In particular, the sub-discipline of finance is important for providing insights into economic cycles, market behaviour and investor decisions. However, since the global financial crisis beginning in 2008, and the ongoing financial instability, there have been calls for academics to engage with new paradigms (Lo, 2011) and in particular to acknowledge the limits of models and theory for practice (Colander et al., 2009). That being said, within the business school environment in which finance resides, the discipline appears to be taking on an increasingly large and prestigious role. Institutions compete for scholars who are able to publish work in the 'elite' financial outlets, which are amongst the most cited of any sub-fields, and thus command scholarly prestige where metrics are taken as the sole measure. However, finance offers universities an advantage along another dimension via its ability to attract high fee-paying post-graduate students. The high returns centred around prestigious finance programmes, and more generally publication in 'elite' outlets have led to investment being skewed both to finance as a sub-discipline and in particular to those individuals within it who are able to publish regularly in these outlets. Such returns skew financial and intellectual capital towards this narrow set of 'elite' outlets that act as lightning rods for resources.

Critics within the academic community have noted the over quantification of finance research (Bennis \& O'Toole, 2005), that neoclassical finance is producing 'nothing new' (Gippel, 2013) and the use of abstract models bearing no resemblance to reality (Krugman, 2009) while others exhort the field to expand quantitative empirical work beyond pre-existing large databases to listen to practitioners (Salmona et al., 2015). More worryingly, the volume of research relating to ethics in finance is very low compared to other areas within business (Bernadi et al., 2008), and evidence that ethics has been generally ignored (Horrigan, 1987) is indicated by the fact that none of finance's 'top' 40 journals or the journals listed in Cabell (2004) indicate an interest in ethics research (Bernadi et al., 2008).

Finance provides a valuable case study as an academic sub-discipline since it is relatively self-contained with fairly clear boundaries distinguishing it from other areas. Unlike the broader social sciences, such as sociology, psychology or even economics, which can be traced back to at least the late eighteenth century (Agarwal \& Hoetker, 2007), finance is a relatively new discipline (Alexander \& Mabry, 1994) that originated in and is still dominated by US scholarship, as we document below.

Finance has obvious practical linkages with the financial services sector yet these appear to be tenuous (see, for example, Coleman, 2014). Beyond direct involvement with firms operating in the sector, finance is an area that is of interest to governments and regulators both in the banking sector and beyond. We argue below that, more fundamentally, finance is the very epitome of emergent trends that will become increasingly pervasive in business and management more generally. As a result of the additional strength of its incentive structures and the nature, objectives and motivations of those who choose to work in the finance area of the academy, finance is a leading indicator of the direction of travel of other scholarly sub-fields in business schools. Ideas from financial economics are increasingly pervading the academic community and society more widely (Dore, 2008). Concerns have been expressed that the 'economisation' or 'financialisation' of management education more generally has been damaging in terms of its effect on the way that research is conducted (Hühn, 2014). This has also led practising managers to adopt an increasingly 'self-destructive world view derived from neo-classical economic theory and applied to critical issues of corporate strategy and corporate governance' (Daneke 
\& Sager, 2015, p. 29). A study of the development of finance therefore has value to the wider research community and the lessons we can learn may help to prevent the issues we document below from becoming endemic across business schools.

In this paper, we explore the development and impact of academic finance with a particular focus on the UK. We believe that it may be helpful to define as precisely as possible, with examples, what we mean by the term 'academic finance', which we use to refer to the scholarly study of financial markets including investments (for example, topics such as: portfolio management, market structures, asset pricing, financial risk management, and concepts of 'market efficiency'), corporate finance (e.g., the mechanisms through which firms raise financing, their decisions about how to use it, dividend policy) and banking (e.g., theories of financial intermediation, bank efficiency). It is our view that the current state of academic finance results from the juxtaposition of two factors: the incentive structures and motivations of scholars of finance on the one hand and a broad (though not universal) lack of interest from the industry, which we discuss in more detail below, in working with these scholars on the other. These two phenomena combine to result in academic finance having much less real world impact than would be expected given its size and alleged intellectual vitality.

The UK setting is of considerable interest from several perspectives. First, the UK has a comparatively homogeneous higher education system and a long tradition of formal, nation-wide research evaluation through the research assessment exercises (RAEs) and more recently the research excellence framework (REF) - see Brooks et al. (2014) and Collini (2012). The REF measured not only the 'quality' of submitted research outputs (journal papers, monographs, book chapters, etc.), but also the 'quality' of a large number of 'impact case studies' which universities submitted as illustrations of the effects that their research was having on wider stakeholders beyond other scholars. The fact that these research evaluation exercises examined work produced before and after the financial crisis respectively provides a useful 'natural experiment' enabling us to examine whether finance research responded and was able to provide potential solutions to this key issue that the world faced. Second, the UK is the number two single-country producer of scholarly finance research after the US (see Brooks \& Schopohl, 2018, Table 5) but as we document below, the former hides in the shadow of the latter. Third, of relevance is the importance of the financial sector in the UK, where London is the world's largest such centre with financial services driving the country's GDP. ${ }^{1}$ The financial sector is a substantial one in the UK, and hence if there is a location where one would expect interaction between academic scholarship and industry, it is an obvious candidate.

Drawing upon UK information enables us to address a number of the issues that are the focus of this work when attempting to evaluate the size of the contribution that academic finance research makes, not only intellectually but also more widely to the economy and society. Specifically, we seek to address the following questions regarding academic finance research:

- Is it growing in volume and 'quality'?

- Is it adopting a variety of methodological approaches and analysing a multitude of data sources?

\footnotetext{
${ }^{1}$ Source: ONS

http://www.ons.gov.uk/economy/grossdomesticproductgdp/bulletins/grossdomesticproductpreliminaryestimate/j ulytosept2016.

$\frac{2}{2}$ The 'quality' of academic research can comprise a variety of different dimensions, including the (methodological) rigour and robustness of the analysis as well as originality and contribution of the findings to the field and the society as a whole. We will argue in the following sections that academic research in finance has improved along the 'quality' dimensions of rigour and robustness whereas it often lacks in originality and contribution, particularly regarding its usefulness for stakeholders outside the finance academy.
} 
- Is it able to provide potential solutions to the key financial issues that the economy or society face?

- Is it widely used by governments, regulators, and firms - both in the banking sector and beyond?

While the UK provides a natural location in which to focus our arguments, there is no reason to suppose that the research environment, incentive structures and end results are any different in finance departments in other parts of the world as formal performance measurement and research evaluations occur in more and more places, including Australia, Hong Kong, Ireland, New Zealand, Poland and Slovakia (Tunzelmann \& Mbula, 2003).

Our contribution is to provide an evidence-based discussion of the paradoxical position of finance which on the one hand is growing in size and methodological rigour as an academic discipline, but on the other is narrow in its geographic coverage and underperforming in producing research which is of value to the wider economy and society. We provide quantitative support for our argument that the latter is an indirect consequence of the former, as 'elitism' and narrowness in publishing objectives serve to crowd out broader contributions and relevance.

The remainder of this study develops as follows: Section 2 describes our methodological approach; Section 3 presents a discussion of the emergence of finance as a discipline for academic study, explains its epistemological position and discusses its nature and extent within business and management research. Section 4 proceeds to examine the features of the research published in the 'top' journals in finance. Section 5 considers whether scholarly research in finance has proved useful to stakeholders outside of the academic community. Section 6 frames our findings in the conceptual framework of Bourdieu and finally Section 7 offers some reflections and conclusions.

\section{Methods and Sources}

Attempting to understand the anatomy of a discipline, even one which is relatively self-contained with fairly clear boundaries and in highly concentrated journal publications, we rely on multiple sources using a mixed methods approach. First, we undertake a systematic evidence-based analysis of the visible characteristics of finance research through analyses of (a) data from the quality assessments of research produced in UK business schools, and (b) publication patterns in the 'top' finance journals. Second, we aim to explain these observable characteristics with reference to the underlying incentive structures and dominant paradigms among finance academics by linking our findings to the prior literature and additional numerical and case study evidence. In this context, we also address the question of the 'relevance' of the produced research for stakeholders outside of the finance academy. Finally, we bring together both strands of the analysis by framing our findings in the conceptual framework of Bourdieu.

Our empirical analysis draws upon two main databases: (1) UK-specific data on two research evaluation exercises - the Research Assessment Exercise (RAE2008) and the Research Excellence Framework (REF2014); (2) international publication data gathered from online journal repositories and journal websites. We complement these databases with a multitude of additional sources, including journal ratings obtained from the Chartered Association of Business Schools' Academic Journal guide (abbreviated as 'the ABS list'), ${ }^{3}$ information on publication characteristics from Scopus, an abstract and

\footnotetext{
${ }^{3}$ We rely on the ABS list to classify journals into different 'quality' dimensions. In particular, the ABS list divides journals into four categories of descending 'quality': $4^{*}, 3^{*}, 2^{*}$ and $1^{*}$ journals. In addition, some of the
} 
citation database of peer-reviewed academic studies, ${ }^{4}$ and funding data from the Economic and Social Research Council (ESRC, the main UK government funding body for social science research).

The two UK research evaluation exercises both provided a panel-based assessment of the 'quality' of research undertaken by UK higher education institutions separately for each subject (referred to as a panel, or more accurately in RAE / REF parlance as a sub-panel). Data from the RAE2008 and REF2014 provide snapshots at those specific points in time of the panels' assessments of the 'quality' of work being undertaken in UK universities over the previous six years in each case (2002-2007 and 20082013 respectively). The RAE / REF only take place periodically and thus data are only available for these specific intervals. While the work being assessed comprises publications in (peer-reviewed) journals, monographs, book chapters and working papers, our analysis concentrates on those outputs submitted to the RAE/REF that represent publications in peer-reviewed journals. The nature and purpose of the RAE and REF are summarised nicely in Brooks et al. (2014, p. 991):

'The RAE [and REF are] evaluation[s] of the 'quality' of research produced by UK universities run jointly by the Higher Education Funding Council for England (HEFCE), the Scottish Funding Council (SFC), the Higher Education Funding Council for Wales (HEFCW), and the Department for Employment and Learning, Northern Ireland (DEL). Any higher education institute in the UK that received research funding from one of these bodies was eligible to participate in the RAE in 2008 and the REF in 2014, and the evaluation was done separately by subject area. The results of the exercises have been used to determine the amount of research funding allocated to universities for their research.'

The REF had the same objectives as the RAE and produced 'quality profiles' (which present the percentage of work that has been assessed as being of each 'quality level') for each submitting department or school, but it introduced a new 'impact' element designed to measure the usefulness of scholarly research to outside stakeholders such as policymakers, corporates and the wider society. Thus the REF comprised an evaluation of both 'outputs' (i.e., published work, mostly in the form of journal articles) and 'impact'. These two elements may have provided opposing incentives for finance scholars, with the former encouraging a narrow focus on 'rigorous' but perhaps even trivial research while the later was very much focused on useful research even if it was not intellectually ground-breaking.

In RAE2008, Accounting and Finance research was assessed by a separate sub-panel to the remainder of Business and Management but for REF2014 the two had been merged. For both RAE and REF, 'quality' was measured on a $1 *-4 *$ scale, with $1 *$ being the lowest and $4 *$ the highest. Changes in the design of the REF enable us to examine the extent to which different disciplines were perceived as

4* journals are classified as 'World Elite Journals' (renamed and defined as Journals of Distinction in the 2015 list), which are defined as 'a small number of grade four journals that are recognized worldwide as exemplars of excellence within the business and management field broadly defined and including economics. Their high status is acknowledged by their inclusion as world leading in a number of well-regarded international journal 'quality' lists.' $4 *$-ranked journals 'publish the most original and best-executed research. As 'top' journals in their field, these journals typically have high submission and low acceptance rates. Papers are heavily refereed. 'Top' journals generally have the highest citation impact factors within their field' (Association of Business Schools, 2010). Although it would be of considerable interest to also examine lower ranked outlets, they number more than 100 journals, each often publishing several hundred articles or more spanning the past two decades. Given that the information has to be coded manually based on at least skimming the article to establish whether it is theoretical or empirical, and if the latter, what is the source of data used, this is infeasible as it would probably take many months of research assistant time.

${ }^{4}$ The Scopus database is provided by Elsevier and covers research outputs from more than 5,000 publishers in the fields of science, technology, medicine, social sciences and arts and humanities (as of November, 2017): https://www.elsevier.com/solutions/scopus/content . 
being able to impact on the economy and society as this element was a formal part of that exercise with the submitted case studies being made publicly available, while we can also obtain a longer view via success in grant applications.

It is important to note that while RAE and REF exercises may have indirectly contributed to the narrowing of research agendas and the focus of interest on publishing in 'elite' journals, this was certainly not the intention of the exercise and successive RAE and REF panels have been at pains to emphasise that all submitted research would be read and evaluated on its merits irrespective of where it is published (or whether it is published in a journal, or as a book or book chapter). Rather, a more plausible source of elitism is the existence and increasingly widespread use of journal ratings lists as the single way that scholarly research performance is evaluated (Willmott, 2011a; 2011b).

Our database of publications in finance 'top' journals is constructed based on searches of journal content via online journal repositories. In particular, we gathered information on the volume of research published, as well as article-specific information on the type of research (theoretical or quantitative empirical analysis), the topic area and the country of affiliation of the scholars and of the data which they used. We focus specifically on the 'top' five journals in finance ${ }^{5}$ - the Journal of Finance (JF), Journal of Financial Economics (JFE), Review of Financial Studies (RFS), Journal of Financial and Quantitative Analysis (JFQA), and the Review of Finance $(R o F)^{6}$ - and manually searched articles published in these outlets between January 1970 and July 2014. Based on a reading of the articles we coded each publication based on its empirical or theoretical nature, and for the former studies, we retrieved information on the type of data employed. ${ }^{7}$ The number of such studies we examine totals $4,769 .^{8}$

\section{The Development of Finance as a Scholarly Field of Study}

This section of the paper discusses how academic finance has developed, in particular over the past decade. We employ data from the UK's RAE and REF to evaluate and compare finance in the context of its wider field of business and management. The use of such data is useful since it enables us to discuss how both the size and the 'intellectual quality' of work in the finance area has changed between the RAE in 2008 and the REF in 2014. We are able to show that 'quality' and quantity have both increased in academic finance over the period, giving the impression of a sub-discipline with much vitality.

Academic research in finance in the UK developed in parallel with, but largely separately from, the growth of the City of London as the world's leading centre for many areas of activity in the financial markets following the deregulation of financial services embodied in the 'Big Bang' and the Financial Services Act of 1986. The two worlds of scholarly finance and of financial market finance have never been closely linked. It is therefore interesting that the legitimacy of finance as an academic discipline and indeed its apparent intellectual strength, which we document in this section of the paper, have been able to develop over the past two decades despite its tenuous connections with real world financial

\footnotetext{
${ }^{5}$ As ranked by their impact factors, all are either ranked $4 *$ on the ABS list or as 'World Elite Journals'.

${ }^{6}$ The Review of Finance started more recently in 1997; it was formerly known as the European Finance Review until 2004.

${ }^{7}$ We use the word 'empirical' here to denote any study that involves the analysis of evidence or data. The vast majority of such studies involve quantitative research using existing secondary datasets; a small number include experiments, case studies or surveys.

${ }^{8}$ Our sampling ends in October 2014. Due to the sheer volume of work required to be evaluated by hand, we sample even years only.
} 
markets. Moreover, as we discuss further in section 5, the advent of the global financial crisis barely dented the self-image of finance academics or raised questions concerning the validity of finance as a scholarly field of enquiry. This has arisen as a result of the separate socially constructed environments in which academic finance and the financial services sector operate, with the former gaining and retaining its legitimacy from internally generated metrics such as 'elite' journal publishing and citation factors. We develop a Bourdieu-esque conceptual framework in which to embed these ideas in section 6.

Within the academy, as the subject grew through the 1990s and beyond, the budgets to pay the salaries of the growing army of finance academics came predominantly from increasing numbers of Masters students, mainly from Southeast Asia and especially mainland China. Mirroring the salaries paid to its graduates in the City, finance Masters programmes attracted a fee premium, generating substantial surpluses for their host business schools and providing revenue to justify above scale payments to finance academics who are able to command 'market adjustments' at many business schools.' Unfortunately, the hiring of finance graduates by investment banks did not provide a strong route to a flow of ideas from academy to firm since new recruits were often subjected to an intensive process of re-programming upon commencing employment, whereby they were indoctrinated in the ways of city finance and told that much of what they had learned on their university degree programmes does not really apply. ${ }^{10}$

Turning now to a consideration of the development of scholarly finance research over time, a report from the RAE sub-panel for Accounting and Finance noted that both the volume of research produced and published in finance, and its 'quality' and 'robustness', have increased markedly over time:

'A major trend over the period of review was the increasing amount and quality of research that has been undertaken in the area of finance. Outputs in the area accounted for nearly $50 \%$ of the total work submitted to the sub-panel, reflecting the vibrancy and increased importance of finance as a subject for scholarly investigation in the UK.' (Ashton et al., 2009, p. 205).

The sub-panel also argued that there had been an increase in the level of rigour of academic research in the area, partly as a result of the increasing availability and use of high-powered computers, sophisticated econometric software, and comprehensive and well organised commercial databases. By the subsequent research evaluation (REF2014), the volume of work in finance had eclipsed that in accounting, with suggestions by the sub-panel that the latter sub-field was in decline in the UK. ${ }^{11}$

Table 1 allows us to contrast the patterns in submissions to the finance sub-panels of the evaluation exercises with submitted outputs across all sub-panels as well as to identify time trends by comparing the RAE2008 submissions with those submitted to the REF2014. As can be seen by the figures in columns (1) and (2) of Table 1, the percentage of all work submitted to a sub-panel that was published in finance journals relative to the total submissions to all sub-panels increased from $8.1 \%$ (i.e. 886/10,900) in RAE2008 (including both the Business \& Management and Accounting \& Finance) to $11.9 \%$ (i.e. 1,142/9,588) in REF2014, demonstrating a modest relative growth in this subject area

\footnotetext{
${ }^{9}$ For example, in its 'Overview 2015-16 Faculty in Higher Education Salary Survey' report, The US College and University Professional Association for Human Resources noted that among 32 disciplines, new Assistant Professors and Associate Professors in finance were respectively in first and third place in the ordering of their salaries as a percentage of the average salary at that rank.

${ }^{10}$ See, for example Fox \& Sklar (2009) and the discussion therein regarding the efficient markets hypothesis.

${ }^{11}$ See Research Excellence Framework 2014: Overview report by Main Panel C and Sub-panels 16 to 26, p.59, which reports that 'there must also be concern about the relatively low numbers of outputs in the more technical areas of accounting, financial accounting, auditing and taxation'.
} 
between research evaluation exercises, but this masks the increasing concentration of finance within 'top' schools. Ranking institutions by their overall RAE2008 grade point averages, the 'top' $5 \%$ of institutions had $14.1 \%$ (i.e. 137/972) of their submitted outputs in the finance area, the institutions ranked in the 'top' $6-20 \%$ had $6.9 \%$ (i.e. $340 / 4,919$ ) of their entry in finance, the institutions ranking in the next $21-50 \%$ by their institution-specific grade point average had $8.7 \%$ (i.e. $307 / 3,545$ ) and the bottom $50 \%$ institutions had $4.2 \%$ (i.e. 102/2,436) of their entry in finance. For REF2014, this had increased to $22.4 \%$ (i.e. $143 / 638$ ), $12.4 \%$ (i.e. $275 / 2,220$ ), $10.6 \%$ (i.e. $232 / 2,187$ ) and $10.8 \%$ (i.e. 492/4,543) respectively. It is instructive that institutions performing best in REF2014 had more than a fifth of all of their outputs in finance with the remaining four fifths spread across all 21 other sub-fields of business and management and this shows that having a high and growing proportion of finance publications in the overall mix was correlated with that school having a high score in the RAE or REF.

Table 1 provides greater detail on the composition of the submitted outputs. In particular, the table provides a breakdown of the outputs by the 'quality' rating of the submitted output itself. To measure the 'quality' of individual outputs, we cannot use the output-specific RAE or REF scores for this since only aggregate scores at a school level were released and not the scores for each individual piece of research. Thus, we refer to the rating of the journal outlet based on the ABS-list to assign each output a 'quality' rating. ${ }^{12}$ In particular, we rate each output assessed in the RAE/REF as either $1^{*}, 2^{*}, 3^{*}$ or $4^{*}$ based on the respective ABS-list rating of the journal in which it is published. To allow comparability between the RAE and REF, we rely on the 2010 ABS rating list - although the list has subsequently been updated in 2015. While we recognise the limitations of ABS journal rating scores as a measure of individual output 'quality' (and indeed we argue strongly against it as a practice below), we employ them to compute summary statistics at the aggregate level.

Panel A focuses on the results from the RAE2008 and Panel B states the results from the REF2014. The figures reported in Panels A and B of Table 1 represent percentages of the work submitted to the RAE and REF, respectively, sorted by the ABS rating of the journal in which the study is published. In particular, Column (1) states the percentage of output published in $1^{*}, 2^{*}, 3^{*}$ and $4^{*}$ finance journals (according to the ABS list journal classification into sub-fields) across all participating UK institutions, while Column (2) provides the corresponding figures for the full Business and Management Sub-Panel (including finance). Hence, Column (2) serves as a comparison to assess the extent to which the submissions in finance deviate from those across the business and management community as a whole. The final rows of each panel provide the total number of papers submitted to the respective sub-panels.

Looking at the figures in Panel A referring to the RAE2008 results, overall 10,900 papers were submitted to the business and management area of which 886 were submitted in the finance area. Out of these 10,900 (886) outputs, $8.1 \%(6.5 \%)$ in all of business and management (in finance only) were published in a $1 *$ journal, $25.2 \%(19.4 \%)$ in a $2 *$ journal, $43 \%(60 \%)$ in a $3 *$ journal and $23.8 \%(14 \%)$ appeared in a $4^{*}$ journal. Comparing these figures with those for the subsequent assessment, the REF2014, in Panel B, the increasing tendency to publish in higher ranked journals is clearly evident and appears even stronger for the finance sub-field ${ }^{13}$ than for the business and management community as a whole. Out of the $9,588(1,142)$ papers in business and management overall (the finance area only), $32.7 \%(25.6 \%)$ of the outputs are published in the highest rated journals. Notably, this represents an

\footnotetext{
${ }^{12}$ Note that while the RAE/REF and ABS list both use a four-point scale, the definitions of 'quality' under each measure are defined differently.

${ }^{13}$ Note that while the RAE 'finance' panel represents finance only, the REF sub-panel comprises both finance and accounting outputs. Hence, the figures of the two panels are not directly comparable.
} 
$83 \%$ increase of the $4 *$ rated outputs for the finance sub-panel over the previous evaluation exercise. This change probably arose as the result of the conflation of several inseparable factors: increasing use of ABS ratings when determining which authors and papers to submit; increasing selectivity where researchers with outputs in lower rated journals are screened out, and potentially an improvement in academic rigour of the submitted outputs (see, for example, Watermeyer \& Olssen, 2016). ${ }^{14}$

\section{$<$ INSERT TABLE 1 ABOUT HERE $>$}

The remaining columns (3) to (10) of panels A and B further classify the participating institutions by their score obtained in the two evaluation exercises. In particular, columns (3) and (4) provide a breakdown of submitted outputs for the 'top' $5 \%$ of institutions by their rating scores in the RAE/REF. Columns (5) and (6) focus on the breakdown of output by institutions ranking among the 'top' $6-20 \%$. Columns (7) and (8) state figures for institutions ranking in the 'top' $21-50 \%$ in the evaluation exercises while columns (9) and (10) provide values for the bottom $50 \%$ of institutions. Looking at these figures, two additional and more important patterns are evident. First, the increasing percentage of submitted work appearing in 'top' rated journals became more concentrated among the 'top' rated institutions. Second, this effect is far more noticeable for the finance area than for business and management as a whole. In the RAE2008, 43.8\% (32.7\%) of work by researchers at the 'top' $5 \%$ of institutions in the finance area (all business and management) was published in ABS 4* journals. In the REF2014 this had risen to $83.2 \%$ (70.4\%) of outputs. In comparison, the percentage of submitted work to the REF2014 that was published in $4 *$ journals among the 'top' $6-20 \%$ of institutions is only $19.6 \%(41.9 \%)$ for finance (business and management). Hence, the proportion of outputs published in the highest rated finance journals for the 'top' $5 \%$ of institutions is more than four times the proportion of that for the 'top' $6-20 \%$ of institutions, indicating the great divide among the 'elite' institutions and the remainder of the UK finance academy in their ability to place their work in the 'top' journals of their field. Interestingly, this divide seems to be considerably less pronounced for the other business and management fields where the proportion of $4 *$ publications for the 'top' $5 \%$ of institutions is less than double the respective proportion for the 'top' $6-20 \%$. With the only exception of the bottom $50 \%$ of institutions for finance (see column (9) of Panel B) these patterns continue the further down we move by the rating scores of the submitting institutions for the RAE and the REF.

Taken together, the figures presented in Table 1 show that finance 'upped its game' considerably, not just in absolute terms but also relative to the rest of the discipline in publishing research outputs in the 'top' journals of its field. In subsequent sections, we argue that this apparent 'quality' is a paradox, and masks important underlying issues with the development of finance as a scholarly field relating to its usefulness and its contribution to the ethical behaviour of practitioners. The figures above also suggest that in the finance area, the work published in the 'best' journals is more and increasingly focused within the 'top' rated institutions compared with the rest of the discipline.

\section{The Research Published in Finance Journals}

While the previous section focused on the state of the finance academy relative to other sub-fields in UK business schools, we now broaden our analysis to an international dimension by analysing the

\footnotetext{
14 Recent survey evidence (Walker et al., 2015) suggests that the ABS list is used ubiquitously both by business schools in the UK (with, for example, $89 \%$ of institutions using it to decide which individuals would be entered into the UK Research Excellence Framework and in hiring and recruitment decision) and by individuals working within those schools (with, for example, $87 \%$ of individuals using that list 'sometimes' or 'almost every time' or 'always' in deciding where to submit their work).
} 
entirety of research published in finance outlets and investigating the publication patterns over time. We focus our analysis specifically on the 'top' five journals in finance ${ }^{15}$ - the Journal of Finance, Journal of Financial Economics, Review of Financial Studies, Journal of Financial and Quantitative Analysis, and the Review of Finance - which are those journals that comprised the $4^{*}$ category of the ABS list in our previous analysis (Table 1).

Although our focus in this study is on the 'elite' journals, Brooks \& Schopohl (2018) provide evidence that the broad subject areas within finance (e.g., asset pricing versus corporate finance), and even the narrower topics within each of these areas, are fairly similar across journals with different ABS list ratings. In addition, they show that the use of methodological approaches other than the quantitative empirical analysis of datasets (e.g., surveys or interviews, case studies, experiments) takes place in just over $1 \%$ percent of published papers. In finance, the ability of 'elite' journals to mould the field and establish the research agendas appears even stronger than elsewhere as citations to articles published in 'top' journals are much more concentrated (Brooks \& Schopohl, 2018).

Publication of research provides not only a measurable output but a way for researchers to obtain recognition for the standing of their work. Thus 'elite' journals will give the authors of work printed therein the highest level of status and therefore the greatest sense of achievement. As in accounting (Lee, 1995), finance is a sub-field where the system of recognition is regulated through the 'elite' journals and the corresponding associations as owners of the journals which are based in the US. Hence, we believe that the findings presented in the subsequent tables based on the sub-set of 'elite' journals provide a good indication of the likely trends across finance journals as a whole.

To evaluate the observable characteristics of finance research and its development as an academic field, we are interested in the volume of finance research published over time as well as the trends regarding methodological approaches and the geographical distribution of research. We will present our findings for each of these issues in the subsequent tables.

Table 2 presents some summary statistics for the papers published in the 'top' five finance journals for each of the decades from the 1970s through to the 2010s. Panel A states the number of articles analysed over the entire sample period (Column (1)) and for each decade (Columns (2) to (6)). Panel B provides a breakdown of the average number of pages per article while Panels $\mathrm{C}$ and $\mathrm{D}$ state the average number of studies per issue and the average number of issues per year, respectively. For each of these statistics, we present a breakdown by journal as well as the aggregate figures in the last row of each panel.

\section{$<$ INSERT TABLE 2 ABOUT HERE $>$}

Taken together, the results presented in Table 2 suggest that the volume of published work has increased markedly over time - for several reasons. Firstly, as Panel A shows the total number of published articles in the 'top' finance journals has increased from 537 studies published in the 1970s (Column (2), Panel A) to 1,359 articles in the 2000s (Column (5)) and already 1,217 articles have been published between January 2010 and July 2014 (Column (6)). This is not only due to an increasing number of journals, but for all outlets except the Journal of Financial and Quantitative Analysis (JFQA), the total number of studies published per decade has strongly increased over time. Focusing on the 'top' journal by impact factor alone (the Journal of Finance, $J F$ ), the number of studies over each decade was 288, 372, 358 and 498 in the 1970s, 80s, 90s, and 2000s respectively. Already thirty years ago, Whitley (1986, p. 173)

\footnotetext{
${ }^{15}$ Although it would be of considerable interest to also examine lower ranked journals, this is infeasible given that the relevant information from each issue has to be identified and coded manually, see further details in Section 2.
} 
attributed the growth in the number of articles published in the Journal of Finance in particular (and corresponding increases in rejection rates) to the formalisation of the 'publish or perish' mentality, and this trend seems to have intensified over the last three decades as our data suggest.

In addition, and as Panel B of Table 2 shows, the average article length across all journals (of the Journal of Finance, $J F$ ) also rose from 14.47 (12.88) pages in the 1970s to 30.54 (37.04) pages after 2010. Hence, the average finance article is now more than double the length of a typical finance article in the 1970s. What is driving this change? One explanation for the considerable increase in the length of articles is the growing demand by journal editors and reviewers for additional robustness tests, which authors now have to perform if they want to get their paper published in a 'top' finance journal. For instance, Siegel (2012) and Hirshleifer (2015), commenting on the increasingly 'excessive' review process with lengthy rounds of revisions, argue that these revisions often achieve nothing more than removing minor blemishes from the paper while artificially increasing article length and that these additional tests often fail to provide new insights to the study. As well as leading to longer times until papers are accepted, Hirshleifer (2015) points out that these lengthy review processes and the obsession with testing all possible alternative explanations can present major impediments for innovative research to find its way into 'top' journals as the innovative nature and the often unconventional design of such studies means that not all blemishes can be removed or all alternative explanations can be ruled out.

Potentially as a consequence of increasing article length and the increasing number of issues per year, the average number of articles published in each issue has actually seen a slight decline over time, especially for the Journal of Finance which used to publish around 20 articles per issue in the 1970s while in the recent decade the average issue of that journal only comprises around 11 articles (Panel C). In comparison, other journals have increased the number of articles per issue, most notably the Journal of Financial Economics (JFE) and the Review of Financial Studies (RFS). Considering the increasing article length for these two journals, the total length of an issue now comprises, on average, more than 210 and 330 pages, respectively (figures derived by multiplying the respective numbers in Columns (6) for Panel B and C). Finally, Panel D illustrates that several 'top' finance journals have significantly increased the average number of issues that they publish per year; again most notably the Journal of Financial Economics and the Review of Financial Studies, which both have almost doubled the number of issues per year over time.

In addition, the volume of published work outside of the 'elite' finance journals has also seen a strong increase over time. For instance, the number of finance journals on the ABS list rose from 67 in 2010 to 104 in the 2015 edition, a rise of over $50 \%$. Although these figures also reflect greater coverage within the list and not only new journals, the rise over time in the number of journals and in the number of articles published in the journals surveyed in Table 2 are indicative that the total volume of research produced in the area is still growing and has not yet reached maturity (as Agarwal \& Hoetker, 2007, argue has already taken place in economics).

A yet unanswered question is what type of research is being conducted by finance academics and which methodological paradigms are most commonly applied in today's finance community. This is a particularly interesting question given that finance sits astride a methodological boundary between scientific and social scientific disciplinary classifications, and has been argued to be 'relatively fluidly framed' in terms of drawing on a wide range of methodologies (Beattie \& Goodacre, 2012). It ought, therefore, to be amenable to a wide range of methodological approaches and could be considered both a social science, with all financial outcomes arising as the result of decisions of those transacting in the markets and the interactions between them, and as a science to be analysed using formal statistical and mathematical methods (McGoun, 1992). However, a strong preference for the positivist approach based 
on formal quantitative analysis of large datasets has emerged in the core literature while case studies or analysis of questionnaires or interview data are eschewed (Ardalan, 2005; Bettner et al., 1994; Frankfurter \& McGoun, 1999; McGoun, 2003; McGoun \& Zielonka, 2006). In addition, there is a perception among finance scholars that theoretical work is the most prestigious, especially if this kind of work focuses on analytical modelling, with practitioner finance the least and quantitative empirical work in between (Whitley, 1986, p. 179).

To test whether these patterns are observable in our dataset of finance publications in the 'top' five outlets, we manually coded each article into whether it applies an empirical research design based on a quantitative analysis of large datasets in line with a positivist research paradigm. The remaining research comprises theoretical work as well as practitioner-based outputs and studies employing alternative (qualitative) methodologies (including interviews, case studies etc.).

Table 3 provides the results of this analysis for each individual journal and across all five journals (last row of Table 3). Column (1) states the absolute number of studies that employ an empirical approach (including all types of analysis with data but predominantly quantitative empirical work) as their core research design while Column (2) provides figures relative to the total number of papers in the sample. Over the entire sample period 3,474 articles are quantitative empirical in nature, representing $73 \%$ of all articles analysed. Looking at individual outlets, the Journal of Financial Economics appears to have a particularly strong empirical focus with 1,060 articles representing $84 \%$ of its total number of publications relying on quantitative empirical analysis. The Journal of Financial and Quantitative Analysis, in contrast, has a comparably low percentage of empirical studies with $61 \%$ of its published articles analysing quantitative datasets. Turning to the remaining columns (3) to (12), we can evaluate the time trend in methodological choices. As is evident across all outlets, each journal has strongly increased its proportion of empirical studies over time so that quantitative empirical analysis has become the dominant type of finance research published in academic journals. Aggregating across all five journals, the percentage of studies involving empirical analysis has increased monotonically through the decades from $53 \%$ in the 1970 s to $84 \%$ since 2010 but most markedly for the Journal of Financial Economics from 33\% to $89 \%$ over the same period.

\section{$<$ INSERT TABLE 3 ABOUT HERE $>$}

This rise is to some degree expectable given the concurrent advancements in computer technology and statistical software that can be used for analysis and the availability of large, standardised 'off-the-shelf' datasets such as the CRSP tapes and Compustat as well as industry vendors such as Thomson Reuters and Bloomberg. However, while the greater availability of standardised datasets has potentially increased research productivity, enabled researchers to empirically address with econometric analysis previously unanswered questions and possibly facilitated comparability across different research, it also introduces new dangers to the field of finance, especially if there is a greater reliance on standardised data sources at the detriment of using a variety of sources. To evaluate whether finance scholars have been making increasing use of standardised datasets and/or have been relying less on unique, nonstandardised sources, we have manually searched the quantitative empirical studies in the 'top' finance journals (presented in Table 3) for references to the underlying data sources that have been employed and we manually coded each study into whether it (a) relies solely on standard datasets, (b) uses nonstandard datasets only, or (c) uses a combination of standard and non-standard datasets. Datasets have 
been defined as standard based on an initial search of the sample studies to identify those data sources that were most heavily used. ${ }^{16}$

\section{$<$ INSERT TABLE 4 ABOUT HERE $>$}

Table 4 provides an overview of the data sources that have been used in the empirical studies, both across different journals as well as over time. Panel A provides the absolute number of studies relying solely on standardised sources (Column (1)) and their proportion relative to all empirical studies (Column (2)), while Panels B and C present the absolute and relative representation of studies using non-standard datasets only and studies using a combination of standard and non-standard datasets, respectively. If we compare the figures for all five journals over our entire sample period (last rows of columns (1) and (2), of each panel), we find that the proportion of standard datasets, non-standard datasets and a mix of the two across all empirical studies is roughly equal with $32 \%, 37 \%$, and $32 \%$ of empirical studies, respectively. ${ }^{17}$ However, these figures belie the shift in reliance on and preference for standard datasets and combinations of standard datasets and non-standard dataset over time. For instance, in the 1970 s, only $22 \%$ of published papers used data from standardised sources (Panel A, Column (4), last row), 64\% used bespoke data (Panel B, Column (4), last row), and the remainder used a mixture of both (Panel C, Column (4), last row). By the turn of the century, 39\% of published papers were using standardised datasets, $29 \%$ were using both while the percentage of work using bespoke data alone had fallen by half to 32\% (all figures taken from the last rows of Column (10) of the respective panels). Hence, researchers seem to increasingly make use of standard datasets or employ non-standard datasets only to the extent that these can be combined with standard sources. In comparison, the sole use of non-standard data is in decline. Interestingly, the Journal of Financial and Quantitative Analysis (JFQA) - the journal that traditionally has had a stronger practitioner focus, particularly regarding questions relevant to the investment industry - shows the strongest reliance on standard sources while the Review of Finance (RoF) has the largest share of non-standard data sources - presumably due to its stronger European connection, whereas the standard databases have a greater focus on the US, as we will discuss later in this section.

Why is it worthy to investigate the type of data sources that finance scholars use? While relying on a standardised dataset offers many benefits to its users, there are dangers inherent in the widespread use of a narrow range of databases. First, if there are any biases or bald spots in terms of lack of coverage, these will be largely undetectable and entirely endemic so that statistical flukes or the results of data mining become established 'stylised facts' which cannot be challenged as there are no independent yet widely respected databases that can provide an out-of-sample validation. ${ }^{18}$ Second, by definition, exclusive use of information from a defined set of data sources narrows the range of possible research

\footnotetext{
${ }^{16}$ In particular we defined standard datasets as comprising the following sources: CRSP, Compustat, CDA/Spectrum/Thomson Holdings data, SEC/Edgar, Lexis/Nexis, IBES, Bloomberg, Datastream, Worldscope, Fama-French database, NYSE / AMEX / NASDAQ / S\&P500 / Dow Jones Universe, Execucomp, SDC, TAQ, Lipper TASS. Non-standard datasets may include empirical work based on data derived from surveys or other field work.

${ }_{18}^{17}$ Figures might deviate from $100 \%$ due to rounding.

${ }^{18}$ For instance, several studies have documented cases of 'backfilling' of data or other forms of ex-post changes to historical records in some widely used databases which cast doubt regarding the reliability and replicability of the results from prior studies that have been published based on these databases. Examples include Gillan et al., (2018) documenting backfilling in the ExecuComp database and Ljungqvist et al., (2009) providing evidence for alterations, deletions, additions, and anonymizations to analyst stock recommendations in the I/B/E/S database.
} 
topics to those for which (mainly US) data are readily available. ${ }^{19}$ This concern reflects the observations on research and publishing in finance by Mulherin et al. (2018) based on their nineteen years of experience as editors of the Journal of Corporate Finance. ${ }^{20}$ The authors state:

'As editors, we have become somewhat concerned about the standards for current research for ... what we have seen in submissions. Relatively accessible data has far out-paced testable theory ... Moreover, the ease of data access often comes at the expense of actually understanding the institutional features that one is studying. Even hard-to-gather data often does not match well with theory. We also find that authors often emphasize the techniques used in their analysis rather than the underlying theory or usefulness of their analysis.' (Mulherin et al., 2018, pp. 121-122)

To be clear, we do not argue against the use of any particular dataset but we suggest that researchers should embrace and use a wide range of data sources, critically evaluate which database best suits their research setting and be mindful of the limitations that the reliance on a confined set of data sources entails.

These findings of increasingly homogenised research designs of finance publications in the 'top' journals correspond well to the results of a recent study of more than 30,000 papers published in finance which revealed that less than one percent of the work examined represents qualitative research such as interviews, case studies, or experiments (Brooks \& Schopohl, 2018). In addition, the study shows that only a very small proportion of the studies could be classified as interdisciplinary (taking ideas or methodologies from other fields), in contrast to other subject areas in social science. The authors also find only modest differences in research methodologies between the 'elite' journals and the remainder. This finding corresponds to the observations by Callen (2015) who in his critical review of financial accounting research asserts that financial accounting suffers from a 'complacent' homogeneity of methodological approaches, a lack of case studies and qualitative analysis as compared to other research streams within accounting, and that financial accounting scholars ignore research in disciplines other than accounting and finance. ${ }^{21}$ Research three decades earlier by Whitley $(1986$, p. 171) had attributed the increasingly pervasive use of 'scientific approaches' in management from the 1950s onwards to their success in military problems during the second world war. The corresponding developments in business finance began in the 1960s and transformed it from being 'largely descriptive' to 'highly mathematical and formal' (Whitley, 1986, p. 172).

The dominance of data analysis as the singular methodological approach also occurs in accounting, but to a much lesser degree, with perhaps $20 \%$ of research using alternatives (Beattie, 2005, Table 3 ). If we

\footnotetext{
${ }^{19}$ In addition, reliance on these datasets can incur substantial financial costs to the academy. For instance, many of the standardised datasets are available via the web-based Wharton Research Database (WRDS), which allows users access to a wide range of financial databases with information on asset prices, company accounts, fund manager holdings, etc. As of 12 May 2016, 25 UK universities subscribe to WRDS among over 400 subscribers around the world (wrds-web.wharton.upenn.edu/wrds/about/index.cfm). Given that a subscription costs a minimum of USD40,000 just for the interface with a typical overall cost including the databases of over USD100,000, this represents an annual cost to the UK academy of over USD2.5 million.

${ }^{20}$ The Journal of Corporate Finance has been classified as a $4 *$ journal in the ABS Academic Journal Guide from 2015 onwards.

${ }^{21}$ Callen (2015) argues that, in comparison to financial accounting, finance research makes use of a variety of empirical tools. We, however, object that this is only an ostensible methodological diversity and, compared to accounting, research in finance is more limited in its methodological approaches due to the virtual absence of any research that uses alternative (qualitative) research methods, whereas accounting scholarship is characterised by a greater breadth of alternative methodologies and the existence of streams of accounting literature relying on a research paradigm other than a positivist approach.
} 
examine the work published in Critical Perspectives in Accounting using Scopus we find that about $64 \%$ of published papers include qualitative or survey work. Even when we compare the accounting 'elite' outlets (according to the ABS list), we find the following: Accounting, Organizations and Society (25\%); Journal of Accounting and Economics (14\%) and Journal of Accounting Research (20\%).

We should note here that there is also important fieldwork that has taken place in finance using a range of qualitative techniques and where much greater insights into behaviour can be obtained than by the sole use of standardised datasets. Several studies use structured interviews embedded within a grounded theory approach as the core research design - for example, Coleman (2015), Holland (2006), Holland (2016) and Lord (2014) all conduct interviews with fund managers as a way to determine various aspects of how they make investment decisions or explain differences in their performance. Chen et al. (2014) employ interviews with bank managers and analysts to examine how intangibles contribute to value creation. Also within this genre of research, Holland \& Doran (1998) conduct interviews with UK fund managers to determine how their relationships with the companies they invest in impacted upon their stock selection weighting decisions, and Holland et al. (2012) use a case study approach with interviews to examine how Japanese financial firms use accumulated intellectual capital in their valuations and decision-making. Using case studies, Holland (1994) develops a set of concepts relating to bank lending relationships. Finally, Hellman (1996) interviews institutional shareholders about how they made financial decisions following the release of relevant new information, finding that the actions were not consistent with aggregate-level findings from the market-based accounting literature.

Qualitative research has also made a contribution to understanding the 2008 financial crisis - for example, Holland (2010) uses a critical synthesis of the literature combined with case studies of banks and identifies a lack of knowledge among board members and senior managers of the key risks that their organisations were facing. He argues that they were not equipped with the intellectual tools needed to adapt to the new situation as the crisis unfolded. Similarly, Tuckett (2009) interviews fund managers to identify the role that psychological factors and in particular emotions play in helping to create a financial bubble which subsequently explodes.

It is clear from the above discussion of several qualitative studies that an alternative research design from the standard analysis using models from financial economics can yield important insights that have the potential to overturn established ideas about how financial markets function. This body of work is also particularly striking since to interview fund managers requires significant prior engagement with them, which as we document below, is a rather rare phenomenon. This would be a revelation to many 'elite' finance academics: actually finding out how someone made a particular choice by asking them rather than trying to infer it from anonymised data that are many steps removed from the actual context of the decision-making process. Another feature of much of this qualitative research is that in the main it is written by scholars based outside the US and focuses on non-US markets, thus significantly adding to the richness and diversity of research in finance.

However, we make two further comments upon these observations. First while qualitative studies exist, they are rare and vastly dominated in number by financial theoretic, mathematical and quantitative empirical financial studies. Brooks \& Schopohl (2018, Table 1), show that less than two percent of work published in a range of finance journals is of a qualitative or experimental nature. Second, in order to find a higher concentration of qualitative papers, one must venture well beyond the 'elite' finance journals and indeed many of the examples above are published in what would usually be considered accounting or generalist rather than finance journals. That this research with a broader and more novel methodological underpinning is not present in the 'top' finance journals is likely to reduce its exposure, 
its impact on future intellectual developments, and its citation rates within the finance community (Judge et al., 2007).

It appears, then, that research in finance lacks methodological diversity, particularly in its 'elite' journals, but what about geographic diversity - i.e., to what extent are the researchers who are producing the outputs published in the five 'elite' finance journals from the US or from other locations? For the sample of studies summarised in Table 2, Panel A, we next determine the country of affiliation of the authors of those papers at the times they were published. In particular, we investigate the percentage drawn from the US. Table 5 summarises the findings of this analysis. Panel A lists the number of published articles with at least one author from a US institution while Panel B provides figures for articles for which all authors are based in US institutions.

Overall, the results in Table 5 indicate that research by scholars at US universities is predominant in the 'top' finance journals, and this concentration has only slightly diminished over time. For instance, the total number of articles with at least one author from a US institution is 4,089 (Column (1), Panel A) which represents $86 \%$ of the entire sample (Column (2), Panel A). This concentration of authorship of finance articles in US institutions seems particularly evident in the 'top' finance journal, the Journal of Finance, where $90 \%$ of the published articles have at least one co-author based in a US institution. One might argue that this reflects the fact that finance as an academic discipline originated in the US and still a large portion of overall scholarship is carried out in the US.

When looking at the breakdown of the share of articles with at least one US-based author over decades, the US-centred authorship of the Journal of Finance has only slightly decreased from $91 \%$ in the 1970 s to $85 \%$ since 2010 . This is surprising, given the volume of work being published in academic finance worldwide. ${ }^{22}$ One particularly interesting case is the Review of Finance (RoF), which is the sole 'elite' journal not linked with a US association but is the journal of the European Finance Association (EFA). For this outlet, indeed we do find a considerably lower share of US-based authors for the articles published in this outlet with an average of $47 \%$ of articles having one or more authors from a US institution. But it is nonetheless still surprising that almost half of all research in the leading European finance journal has at least one author based in the US.

\section{$<$ INSERT TABLE 5 ABOUT HERE $>$}

Turning to Panel B, we now look at the proportion of articles that are solely authored by scholars affiliated to US institutions. One might argue that this measure provides a better indicator of US-based authorship concentration as the figures presented in Panel A of Table 5 could also be in line with an increasingly international research setting where authors across multiple countries and continents collaborate. Indeed, the share of articles for which all authors are affiliated to US institutions is somewhat lower, with $70 \%$ of all articles having only US-based authors (Column (2)) while this number has decreased to $54 \%$ for the most recent decade (Column (12)). Yet, in all journals but the Review of Finance, the proportion of articles solely authored by US-based scholars is still around $50 \%$, even since 2010. While the nature of our data does not allow us to evaluate why the authorship of 'top' finance publications is still heavily US centred, later in this article we will discuss some implications that might result from this geographical concentration.

\footnotetext{
${ }^{22}$ Brooks \& Schopohl (2018, Table 5) show that the percentage of articles authored by US-based scholars is only $25 \%$ and $30 \%$ for the journals ranked at $2 *$ and $3 *$ respectively.
} 
We move next from looking at the affiliations of authors publishing in the 'elite' finance journals to looking at the geographical coverage of their data. Are the US-based academics that predominated in Table 5 primarily using US data or are they studying a more internationally diverse set of countries? There is, perhaps surprisingly, almost no analysis of the nature of the data analysed by finance academics despite the volume of such research produced. The study that comes closest to our objectives is due to Karolyi (2016). He shows that only $16 \%$ of studies in the 'top' four finance journals over the 1990-2011 period involve non-US markets. He refers to this as a 'home bias' - a term used in finance research to refer to the phenomenon where investors disproportionately place their wealth in local markets and shun those in other regions or countries. Yet his use of the term is a slight misnomer, since his core focus is on the data employed in the studies rather than the country of affiliation of the authors.

Table 6 investigates this issue by examining the country focus and sources of data used in studies published in the 'elite' finance journals. We provide a more detailed analysis of the 'top' journals than is available in Karolyi (2016). In particular, Panel A of Table 6 states the proportion of empirical articles that use non-US data only and compares this figure over time, whereas Panel B provides the corresponding figures for the proportion of articles that solely rely on US data where US data is defined as data covering US markets and the US geographical region more generally. The remaining two panels concentrate on multi-country data where Panel $\mathrm{C}$ focuses on datasets spanning multiple countries including the US while Panel D provides a breakdown of articles with multi-country data excluding the $\mathrm{US}^{23}$

\section{$<$ INSERT TABLE 6 ABOUT HERE $>$}

Overall, the results presented in Table 6 indicate a heavy reliance on US datasets among quantitative empirical studies. For instance, Columns (1) and (2) of Panel B show that 3,008 articles representing $89 \%$ of all such studies published in the 'top' five finance journals rely solely on datasets covering the US, while only 162 papers representing $5 \%$ of empirical studies employ a single country setting other than the US (Columns (1) and (2), Panel A). An aggregate of 206 studies, i.e. 6\% of all empirical publications, use multi-country datasets (figures derived by aggregating numbers in Panels $\mathrm{C}$ and $\mathrm{D}$, for Columns (1) and (2), respectively).

Additionally, our results suggest that the pervasive use of US data has hardly diminished over the past half century. Panel B shows that in the 1970 s, $93 \%$ of quantitative empirical studies used only US data (Column (4)), which fell to $86 \%$ in the 2000s (Column (10)) before increasing again to $90 \%$ since 2010 (Column (12)). However, much of this reduction represents a switch to multi-country studies still including the US (see Columns (4) and (12), Panel C). The percentage of studies studying a single market but not using any data from the US, averaged across all journals, has increased from $2 \%$ in the 1970s to 5\% since 2010 (Panel A, Columns (4) and (12), respectively). Again, the Review of Finance is a particularly interesting case since, being the official journal of the EFA, one might have expected work that it published to have a more European flavour. However, worryingly from the perspective of diversity, there has been an increase in the percentage of studies using only US data from $50 \%$ in the 1990s to $78 \%$ since 2010 (Panel B, Columns (4) and (12), respectively), and a reduction in the percentage of studies not using US data at all from $25 \%$ to $17 \%$ over the same period (sum of numbers in Panels A and D in Columns (4) and (12), respectively). In that sense, its geographic focus of analysis is now virtually indistinguishable from the US journals that it seeks to emulate and it no longer primarily serves the European finance community. It would appear that the rules of the game in finance are so

\footnotetext{
${ }^{23}$ We excluded empirical studies for which we could not unambiguously determine the geographical coverage of the data from the sample.
} 
well established that ceteris paribus, most of the 'elite' research (by virtue of being published in an 'elite' journal) is based on US data; to do otherwise would be irrational for any ambitious, narrow careerist academic anywhere in the world and thus the preponderance of such work in the 'top' journals is a self-fulfilling cycle.

In order to determine to what extent the strong focus on US data is driven primarily by US authors and whether non-US authors may adopt a more diverse geographical coverage of their research, Table 7 presents the figures for the data coverage of quantitative empirical publications by author location. In particular, we distinguish between publications for which none of the authors is affiliated to a US institution (Panel A), publications for which all authors are from US institutions (Panel B) and publications for which at least one author is affiliated to a US institution (Panel C). Columns (1) to (4) correspond to the geographical coverage of the data used in the publication and the categories are the same as the ones used in Table 6. As can be expected, US authors make predominant use of US data with $94 \%$ of the empirical publications with sole US authorship relying on US data only (Panel B). In addition, figures in Panel $\mathrm{C}$ suggest that having at least one US author among the author group encourages a strong US focus as well with $92 \%$ of these publications using US data only. In comparison, their use of non-US data is negligible with 3.5\% in total (sum of numbers in Columns (2) and (3) of Panel C), and this pattern has remained relatively stable over time. What is more interesting is the geographical coverage of empirical research conducted by (groups of) authors from non-US academic institutions only, presented in Panel A. While we find the highest degree of non-US data usage among all other author sub-groups with around $18.5 \%$ of their publications relying on data from a single country other than US or multi-country data excluding US (sum of numbers in Columns (2) and (3) of Panel A), US data still constitutes the dominant research focus with $71 \%$ of all quantitative empirical studies conducted by non-US based authors using US data only. What is more surprising is that the strong US focus of non-US based authors initially decreased over time from $82 \%$ in the 1970 s to $61 \%$ in the 1990s; but the last two decades have seen a strong re-focus on US data use by non-US based authors with $76 \%$ of publications since 2010 relying on US data as their sole geographical coverage.

\section{$<$ INSERT TABLE 7 ABOUT HERE $>$}

Our findings echo those of Das et al. (2013), who focus on the country affiliations of the researchers publishing in a very large number of economics journals over the $1985-2005$ period. They find that the number of papers published by US-based authors is at the expected level given the size of the population and its level of economic development. However, articles which employ US data comprise three times more of the publications in the very 'top' journals compared with those based on analysis from other countries. Das et al. argue that evidence-based economic policy in developing countries is hardly possible since globally, universities are not generating the evidence. Their research was subsequently picked up by The Economist in an article arguing that the lack of research on developing economies results not only from a relative paucity of high-quality data on the latter, but also from the lack of prestige of such research. ${ }^{24}$

The geographical concentration of the subject matter of empirical work published in the 'top' finance journals is much greater than that in economics. According to Das et al. (2013, p. 112), the leading journal, the American Economic Review, published 39 papers on India, 65 on China, and 34 papers on sub-Saharan Africa over a 20-year period to 2005; by contrast, the Journal of Finance published four

\footnotetext{
24 'Academic research: The useful science?' The Economist, 4 January 2014.
} 
papers using Indian data, seven on China and one on South Africa. ${ }^{25}$ Willmott (2011b) argued that 'widespread use of the ABS list by university managers induces a particular, North American-centric model of scholarship' which fits poorly with the broader styles of research conducted in the UK. An exclusive reliance on ranking lists by some university managers is unfortunate from many perspectives, in particular since research on emerging markets is likely to have greater social value and a higher impact on policy than that on the US (Das et al., 2013). There are discussions in the accounting literature of a tendency among US academics to be unwilling to recognise the contributions made by scholars and in journals edited outside of the US (e.g., Humphrey, 2008). In finance we can add a new dimension to this issue: namely a lack of interest in, or a doubt regarding the credibility of, research conducted using non-US data so that many European researchers prefer to employ US data even where their knowledge of the country setting and institutional framework is likely to be much weaker than for their country of residence.

To further contextualise our findings, we compare 'elite' journals in accounting, defined as World Elite Journals, to provide consistent juxtaposition to the 'elite' finance journals, using the country facility in Scopus with the proportion of US-based authors to total being provided in parentheses: Accounting, Organizations and Society (29\%); Journal of Accounting and Economics (92\%) and Journal of Accounting Research (84\%). These ratios suggest that while a number of journals are highly focused on US authorship, Accounting, Organizations and Society is not and thus accounting researchers have at least one 'elite' journal which routinely publishes research from a more international authorship base, which is not the case for finance.

The dominant US focus of the finance research agenda is troubling for many reasons. It is clearly evident that almost however defined, all of the 'top' finance journals are based in the US and naturally those journals are particularly keen to publish work of relevance to US financial markets. Some argue that researchers working outside the US are therefore at a disadvantage in terms of the likelihood of being able to publish there. To improve their chances, many researchers based outside the US nonetheless choose to employ US data even if international equivalents are available with intellectually interesting problems that are unique to other regions in the world (e.g. developing countries) as these are considerably more difficult to publish in the 'top' journals thereby establishing a convention (Young, 1993) through the positive feedback effects of journal acceptance. ${ }^{26}$

The conventions of 'top' ranking journals have consequences for faculty mobility, where scholars must research on prescribed topics if they wish to have $4 *$ journal publications and be in demand in the job market. As Bernadi et al. (2008) note, ethics may not be considered as favourably as basic research by the academy and this in turn is linked to faculty reward systems. We have shown earlier that this basic research employs largely US-centric data which means that academic finance does not contribute to the common good of developing countries any more than it does to the stability of financial markets.

\footnotetext{
${ }^{25}$ It is important to note that these numbers refer to a sampling that only considers even years. Hence, the actual number of articles covering these regions might be higher. Nevertheless, the numbers still appear small compared to those for the American Economic Review reported in Das et al. (2013). In addition to the articles in the Journal of Finance covering India, China and South Africa, there are around 60 multi-country studies that include the US and a range of others but predominantly Europe and Japan.

${ }^{26}$ Palea (2017, p. 59) in her assessment of accounting research conducted at European institutions arrives at a similar conclusion stating that accounting scholars underperform in producing research that addresses questions of relevance to the European Union society and attributes this finding to 'the widespread practice of assessing academic quality based on journal rankings, which tends to reward conformity to the US-mainstream'.
} 
More broadly, there are also dangers for UK universities in adopting the US approach of vastly privileging research in the 'elite' journals. A historical strength of the UK academy is that, unlike the US, there is depth with excellent research being conducted at almost all UK universities, ${ }^{27}$ and the danger is that when research is evaluated in a unidirectional fashion based solely on journal ratings, a vast underclass of universities unable to achieve this emerges. Over the past decade we have witnessed several highly rated UK-based universities trying to 'break away from the pack' by becoming like US universities on British soil - embracing the American research agenda, hiring students with PhDs from 'top' US schools and paying far higher salaries than other UK universities could afford.

This section has attempted to examine the nature of academic finance in terms of whether it is theoretical or empirical, if the latter the nature of the data used, and the country of affiliation of the authors and then to discuss the likely consequences of the trends that we note. We observe a sub-discipline that is narrowly focused, at least at the 'top' end, with an increasing preponderance of quantitative empirical studies, primarily using standardised datasets and where US markets are the object of study and the authors of the research are also based in the US.

\section{Is Research in Finance Useful?}

It is clear from Table 1 that successive research 'quality' assessments in the UK have succeeded in driving up the average 'quality' of research - at least if we regard the rating of the journal in which the research is published as a good indicator of the 'quality' of the article itself - and driving out (or underground) 'weak' or 'non-rigorous' research. But to what extent has this 'higher quality' research been useful? Whether relevance has been sacrificed at the altar of rigour is an issue that has concerned researchers in the wider management literature for many years, and very practical work lacking in rigour is likely to be promptly dismissed (Gulati, 2007, p. 778). Yet while a solid methodological foundation might be a requirement for producing genuinely insightful knowledge that can inform practice, it is not sufficient (Vermeulen, 2007, p. 755) and the reduction of a model's popularity with practitioners as a result of its real-world failure (e.g. the capital asset pricing model in finance) does not appear to dent its intellectual value (Whitley, 1986, p. 185).

We draw a distinction here between scholarly research that is empirical (i.e. involving the use of real data) and research that is useful. While our findings in Table 3 indicate the widespread use of quantitative empirical data to test theories in finance, it does not necessarily follow that such output will be useful to practitioners or policymakers, in the same way that purely theoretical research is not necessarily useless to them.

Vermeulen (2007) writes of the existence of two feedback loops in research: one where scholars read the work of other scholars and then produce new research which is then published in similar journals and read by those original scholars; and the other where practical issues inform scholars' research agendas and in turn they contribute to solving those problems and imparting their knowledge through executive education. He argues that while the former loop is deeply embedded in academic research culture, the latter is underdeveloped. There is much research in the wider business and management literature too indicating that over time scholarship has departed from real-world problems (Rynes et al., 2001; Vermeulen, 2005; Palea, 2017).

Critics note that new theoretical contributions in finance have not developed from the logical positivism dominant in the 1960s and 1970s, resulting in finance scholars predominantly dedicating their time to

\footnotetext{
${ }^{27}$ The results from REF2014 suggest that $68 \%$ of all institutions submitting to the business and management sub-panel had at least $10 \%$ of their research rated at the very highest $4 *$ (world leading) level.
} 
testing and partly revising existing theories rather than building new theory (Gippel, 2015a). A key criticism that has been levelled against academic research in finance is that, in parallel with economics, the global financial crisis that hit in 2008 apparently came as a great surprise. The RAE2008 Accounting and Finance sub-panel wrote hopefully that,

'...the recent financial crisis has raised questions as to the usefulness of some or all of the techniques studied that, presumably, will lead to further research in the future.' (Ashton et al., 2009, p. 206).

Yet rolling forwards to the comparable report produced by the Business and Management sub-panel in REF2014, this change of focus had patently not been found to have occurred:

'Very little submitted work focused on substantive investigations of the financial crisis, its causes and implications, and there was no discernible change in the nature or type of research undertaken since the crisis, nor the basic underpinning of accounting and finance functionalities in economic systems.' (p. 59)

Numerous researchers have attempted to study the financial crisis and to identify its causes after the event (e.g., Holland, 2010; Tuckett, 2009), but Gendron \& Smith-Lacroix (2015, p. 84) question whether any substantive change in finance research has taken place since then. In a rather neat irony, in RAE2008, the economics sub-panel awarded a self-congratulatory highest average score of all subpanels at the time of the global financial crisis which few economists had seen coming (Gillies, 2012). The latter was much to the amusement of Her Majesty the Queen, so that '.. in [their] hour of greatest need, societies around the world [were] left to grope in the dark without a theory' (Colander et al., 2009, p. 2). Where there were significant voices of warning before the crisis, as before numerous other financial crashes, they were marginalised within the discipline (not being present in any of the 'elite' outlets), and ignored by most practitioners (e.g., Kindleberger \& Aliber, 2005; Shiller, 2000). Writing in 2008, Richard Dale further commented:

'What we have witnessed in recent months is not only the fracturing of the world's financial system but the discrediting of an academic discipline. There are some 4000 university finance professors worldwide, thousands of finance research papers are published each year, and yet there have been few if any warnings from the academic community of the incendiary potential of global financial markets. Is it too harsh to conclude that despite the considerable academic resources that go into finance research our understanding of the behaviour of financial markets is no greater than it was in 1929/33 or indeed $1720 ?^{, 29}$

Although the strength and vitality of finance as an academic discipline seems indisputable prima facie given the evidence we presented above, it is questionable whether it has a real understanding of many aspects of the changing nature of global financial markets, described by Lo (2011) as a 'new world order' of increased volatility and larger, faster, more diverse equity markets. We interrogate the relevance of finance research by asking: To what extent has finance research engaged with and been informed by practitioners in their daily decision making? To what extent do practitioners make use of academic research? Finally, why has finance research contributed so little to the ethical behaviour of finance practitioners?

\footnotetext{
${ }^{28}$ Research Excellence Framework 2014: Overview report by Main Panel C and Sub-panels 16 to 26, REF2014, January 2015

http://www.ref.ac.uk/media/ref/content/expanel/member/Main\%20Panel\%20C\%20overview\%20report.pdf

${ }^{29} \mathrm{http}: / / \mathrm{www} . v 0 x e u . o r g /$ article/financial-meltdown-academic-crisis-too.
} 
One way that the academic finance community could have interacted with the industry is by providing independent verification of the soundness of the methodologies employed by practitioners and public legitimacy for their existence and value in parallel with the function of accounting academics as sources of prestige for large auditing firms (e.g., Burchell et al., 1980). Yet it appears that the industry does not feel the need for such legitimacy, even in the face of harsh criticism ('banker bashing') following the global financial crisis in 2008.

To what extent has finance research engaged with and been informed by practitioners in their daily decision making?

The evidence in Section 4 showed that academic finance is dominated by quantitative empirical studies and by US scholarship. This begs a question as to whether the kinds of research being published, which arose either from intellectual curiosity or the reward structures that academics face, are relevant for policymakers or for financial market practitioners. Thus, in this sub-section we discuss, in broad terms, whether finance researchers have the skills and the incentive structures to be able to address the big issues of our times. ${ }^{30}$ Unfortunately, it would seem that today's finance academics have inherited a legacy of research abstracted from practice. As long ago as 1968, Durand wrote that finance research did not even address the more mundane issues of the times:

'The actuaries have managed to keep at least one foot on the ground by addressing themselves to workaday problems requiring mathematical solutions; and although these problems may seem dull and uninteresting to the new finance men, they are at least tractable, and usable solutions are forthcoming. The new finance men, on the other hand, have lost virtually all contact with terra firma. On the whole, they seem to be more interested in demonstrating their mathematical prowess than in solving genuine problems; often they seem to be playing mathematical games.' (Durand, 1968, p. 848)

The financial crisis led some commentators to suggest a failure of the entire neoclassical, rational agent basis of free markets that underpins finance theory and to calls in the media and populist outlets for a paradigm shift. Academic finance is seen as bound by a fixed set of methods and the interaction between academics and practitioners is either weak or non-existent. Beattie \& Goodacre (2004) use data from the British Accounting Review Research Register of accounting and finance academics in the UK to show that the percentage of faculty with a $\mathrm{PhD}$ doubled to 30 between 1991 and 1999, while the percentage with professional qualifications reduced from 81 to 58 over the same period, indicating an introversion and a weakening link with the industry. Several of the key failings of the part of scholarly finance dealing with investments are that it cannot capture human behaviour, it cannot explain bubbles and crashes, it fails to allow adequately for spillovers and contagion between markets and asset classes, and it is too mathematically complex yet still implausibly distant from reality. The elevation of theory as an object of beauty and forming the underpinning of finance is severely wounded by the implausibility of its assumptions (Ardalan, 2008; Kay, 2012) and these assumptions are not vocally communicated to the users of the models (Colander et al., 2009). Financial market dynamics are sometimes argued to be too sophisticated to be amenable to accurate mathematical modelling (Fabozzi et al., 2014, p. 15). Many of the fundamental tenets of modern finance theory, such as the value of diversification, the use of variance or value-at-risk as risk measures, the efficiency of markets, and the

\footnotetext{
${ }^{30}$ Note that our purpose here is not to add to the debate on whether finance theory could or should have predicted that a financial market crash was imminent, even if not occurring at precisely the time that it did in 2008.
} 
rationality of financial market participants, have all come into increasing question since the financial crisis, yet no radically different approaches have emerged as a result (Gippel, 2013).

So-called econophysics, or in our case mathematical finance, which uses advanced mathematics and approaches from physics to solve specific problems in finance, principally relating to the pricing of exotic derivatives, became highly popular in the 1990s and 2000s but faded back to obscurity after the financial crisis in which it was implicated as a key perpetrator (Taleb, 2007; Triana, 2009). Thus while finance has attracted many bright mathematicians and physicists, their limited knowledge of the fundamentals of the businesses that they were pricing could easily imply that they fail to see what to a layperson would be blindingly obvious. We thus have a situation where there are two distinct subcommunities: one using sophisticated models drawn from economic theory and another using largely atheoretical but still sophisticated quantitative models drawn from physics or engineering. These two research areas have developed largely independently from one another with few connecting points, except that neither has proved a particularly insightful framework for contributions to practice.

Zingales (2015, p. 1359) noted that 'financial economists have been too proud of the technical achievements ... of our discipline and too complacent of its shortcomings' which is supported by Gippel's (2015a) research on the views of 'top' finance academics who regard the models used as neutral and therefore not responsible for the global financial crisis but blamed practitioners for their misuse or misunderstanding of the models. Is this complacency on the part of academics perhaps due to the fact that, as McGoun \& Zielonka (2006, p. 53) argue, 'the use of mathematics is correlated with status' and thus academic identity is at stake?

In numerous sub-fields of business and management there is a feeling among scholars that research has become standardised in terms of topic, approach, methodology and style of writing. For example, there is almost a complete lack of interdisciplinary research in finance, it constituting only around $3 \%$ of published studies (Brooks \& Schopohl, 2018). Alvesson \& Gabriel (2013) lament what they term the 'standardisation of research and publications into formulaic patterns that constrain the imagination and creativity of scholars and restrict the social relevance of their work' (p. 245). They argue a key problem is that most research originates from a gap-spotting mentality where research becomes aimed at an increasingly narrow and purely academic audience. One could evidently apply this critique to research in finance, a subject whose lack of paradigmatic diversity is attributed as being the cause of its failure to explain relevant real-world phenomena (Gendron \& Smith-Lacroix, 2015).

\section{To what extent do practitioners make use of academic research?}

The view that academic research in finance is having insufficient practical impact is widespread but not universally held, and is naturally contested by many finance academics. Macey \& O'Hara (2009) provide three examples of such research that have each had a profound impact on the financial markets. First, an article on why market-makers only use even eights in price quotations; second, on the prices at which mutual funds bought shares from and sold to their investors to extract money from them; third, on the back-dating of stock options. In all three cases, significant regulatory actions and law suits followed. Macey and O'Hara also document three studies which they feel ought to have influenced policy but which were overlooked. Their conclusion is that researchers only influence policy in the regulation area when it is politically expedient for the authorities to take heed - for example, when there is popular will driving regulatory change following a crisis.

Thus undoubtedly there are examples of academic finance research having profound impacts on policy and practice (see also Balatbat et al., 2004; and Frino et al., 2007). But given the vast number of papers published in the finance area, and the enormous resources that are devoted to academic research in 
finance, it is legitimate to question whether researchers are pulling their weight in influencing policy and practice compared with other sub-fields in business and management and beyond. If not, why has this been the case?

It is possible that the UK Government introduced impact assessment into the REF2014 partly to mitigate against the increasingly inward looking nature of academic research. In business and management, the most impactful research is mostly not being done by the most prestigious universities on other measures $^{31}$ which usually prefer to focus on 'elite' journal publishing rather than investigating real world issues. Finance ought to be a subject area where there is much fruitful interaction and crossfertilisation between industry and the academy. Banks and securities firms are employers of large numbers of doctoral graduates and utilise sophisticated econometric models, yet the bridges between the two worlds are surprisingly sparse and narrow (Rooney et al., 2013). One factor seems to be the dominance of sophisticated quantitative models taught in universities which have limited real-world value as investment practitioners use alternative techniques (Carter \& Van Auken, 1990; Veit \& Cheney, 1984). Coleman's (2014) interviews with 34 fund managers on four continents concluded that finance theory was of limited relevance because quantitative approaches require data about a future that is unavailable, and because it ignores practitioner objectives and skill, and the plethora of contextual data available to them, such as private information (Drachter et al., 2007).

Banks appear desperate to 'own' all of the models they employ and are obsessed with secrecy, preferring to acquire research knowledge from private sources (Miles et al., 2003). In particular it has been noted that universities and other public institutions are not involved in financial services sector networks so that the bodies which represent the industry do not have members from either the academy or the government (Rooney et al., 2013). This lack of involvement in industry networks and hence the lack of influence over the application of mathematical models can have negative implications for ethics (Pavelin \& Porter, 2008) as it fosters the reification and misuse of mathematical models due to their abstraction from reality. Keasey \& Hudson (2007) liken academic finance to a 'house without windows' where those in an ivory tower have discussions amongst themselves and refuse to engage with the industry or investors, thus completely losing the context in which, and the reasons why, particular financial decisions are made. ${ }^{32}$ Such an approach, according to Keasey and Hudson, acts as a protective barrier to questions of the validity and relevance of scholarly finance research where career structures and rewards, the education of students and journal publication objectives all serve to perpetuate the status quo.

A scientific revolution where new and better approaches and models emerge could have been generated by the industry. This, however, seems unlikely since banks and securities firms have been reluctant to make anything more than trivial financial contributions to the academy, even in the 'fat years' prior to the financial crisis, due to their widespread and self-fulfilling perception that universities have little to offer. ${ }^{33}$ While there are examples of banks and securities firms providing time, data, and expertise in working with academics to address intellectually challenging and real-world relevant research problems

\footnotetext{
${ }^{31}$ In the Business and Management area, the Universities of Aberdeen, Bournemouth, Brighton, Ulster came within the 'top' ten when ranked by the percentage of impact rated at $4 *$, while the London Business School was outside of the 'top' 30 on the same measure. The correlations between the percentages of $4 *$ work on the impact measure and the percentage on outputs (i.e., publications) is only around 0.4 .

${ }^{32}$ Fogarty $(2018$, p. 55) arrives at a similar conclusion regarding the state of accounting research and asserts a major schism between accounting practitioners 'who do not really want academic contributions and a group of academics who cannot provide practice-based contributions'.

${ }^{33}$ Although Whitley (1986, p.172) mentions corporate treasury departments providing 'substantial support for research', we argue that this has not been pervasive, either over time, throughout the discipline or geographically.
} 
- as we have highlighted with the field studies discussed above - such working relationships are rare given the strength of the subject within the academy and the size of the financial services sector in the UK.

Casual discussions with many financial market practitioners reveal a general lack of interest in academic research and a sense that none of it is relevant to them. For instance, Mobley \& Kuniansky's (1992) survey of finance practitioners found that the majority rated finance academics as average or below in their knowledge of the problems facing business and their abilities to solve practical financial problems. This low rating was extended to academics' knowledge of business in general and their ability to generate creative ideas and partially explains the lack of linkages between the academy and the industry documented above and in, for example, Coleman (2014). By contrast, $60 \%$ of the academic research on auditing that was surveyed by Gendron \& Bédard (2001, p.358) and published in journals other than Critical Perspectives on Accounting involved auditing firms somewhere in the process - either as funders, providers of data or even as co-authors.

Ironically, for better or for worse, the leading investment banks are mainly staffed at all levels by graduates from 'elite' universities and so to the extent that banks maintain any links with the academy whatsoever, these are almost exclusively with institutions at the top of the league tables, even though the most market-relevant research is mostly being conducted by lower ranked universities as we documented in a previous sub-section. A further particular issue in the UK is the lack of a professional body of the size and stature of the Institute of Chartered Accountants of England and Wales (ICAEW) to provide an interface between academics and the industry. ${ }^{34}$ Indeed, such professional accounting bodies (also including the Institute of Chartered Accountants of Scotland, the Chartered Institute of Management Accountants, and the Association of Chartered Certified Accountants) are active in providing research funding and other support for projects in the finance sphere where they overlap with those of professional accountants, such as corporate finance or corporate governance. But such interactions are not a substitute for support from within the core of the finance industry that would enable funding access for a wider range of topics including, for instance, trading and portfolio management that would be of less interest to the accounting bodies.

Finance scholars have struggled to obtain funding from competitive government-backed funding bodies as evidenced by the small number of grants such researchers receive compared with other sub-fields within social science more generally. As a demonstration of the latter, we examine the funding areas of the UK's largest public funding provider used by business school scholars, the ESRC. Figures from their web site ${ }^{35}$ suggest that finance as a subject area is attracting a minuscule number of research grants. We manually trawl their list of titles of research projects that were funded, and of the 11,565 projects listed during the 36-year period from 1979 to 2015, only $282(2.4 \%)$ were in the finance area when broadly defined (including insurance, banking, housing markets etc.) but if we restrict our analysis to the 'core' of academic finance where the topics were specifically in the investments or corporate finance areas, there were only 82 such successful applications ( $0.7 \%$ of the total). In this context, finance is competing not just with other sub-fields within business and management, but also with all of social science including economics, psychology and sociology. Yet given the size and economic importance of the financial markets in the UK, and given the number of academics working in the finance area

\footnotetext{
${ }^{34}$ The Institute for Quantitative Investment Research (INQUIRE) and its counterpart the Q-Group in the US are valuable exemplar in terms of bridging the gap between the academy and industry in finance in but they are too small and narrowly focused in investment management to make real inroads into university research agendas.

${ }^{35}$ www.esrc.ac.uk, collected in May-June 2016.
} 
(c.11\% of all outputs submitted to the REF2014 Business and Management sub-panel were in the finance area), the tiny number of grants is worrying. More recently, the ESRC has also begun to display 'impact case studies' on its web site, and there is a total of 166 listed starting from the year 2000 but with the majority being much more recent. Of these, $3.9 \%$ are broadly related to finance but just a single case study $(0.65 \%$ of the total $)$ is in the core of finance. ${ }^{36}$

We also conduct a similar analysis of the case studies submitted for REF2014 by manually examining each one and identifying those that are in the finance area. Interpreting the subject broadly, a total of 32 case studies fall within the area (7.7\%), and are heavily concentrated among a small number of institutions, with $80 \%$ of submitting universities having no case studies in finance at all. If we take a narrower view of finance and remove areas such as development finance, banking and insurance, we find only four case studies in the core of finance (two in the investments area and two on corporate governance), less than $1 \%$ of the total, which were concentrated within just two universities. We can thus conclude that despite the apparent growth in 'top' journal published outputs, the research at the heart of finance remains locked in the ivory towers, not being used by wider stakeholders and neither influencing regulatory/government policy nor influencing the way banks or companies conduct their businesses.

In terms of the parlance used by sub-panels in the REF, historically research was judged primarily on its originality and significance: is the work saying something new and exciting, and does it take the subject forward? Rigour, at least as defined in terms of methodological 'soundness', 'robustness' of techniques and sizes of samples employed, was highly variable. But over time the importance of this attribute, and more widely of telling a rigorous story, has become primal. Nearly all research in finance is now well written, well 'positioned', employs sophisticated techniques with enormous samples and engages in pages and pages of additional supplementary analyses for 'robustness' (Gippel, 2015a). However, the bulk of this research pursues only marginal contributions within an established paradigm using taken-for-granted quantitative research methods (Ardalan, 2008; McGoun, 2003). Perhaps a sideeffect of the increasing focus on methodological soundness is that creativity and experimentation in the research has been diminished so that big new ideas struggle to emerge and research agendas are increasingly homogenised. Thus, although the work is now of 'better quality' and more polished than ever, increasingly, few outside of the academic environment want to read it (Trahan \& Gitman, 1995). In the accounting area, Gendron \& Bédard (2001) and Bell \& Wright (1995) suggest that, by contrast, auditing research is relevant for and useful to auditors.

If the academy were to move from its current position to one where there is more cross-fertilisation between the financial services industry and universities with the former providing research funding and other resources for the latter, there is a danger that scholarship would become 'captured' by the banks, creating a distorted set of incentives to produce only research that fits with the narrative which they wish to put forth (see the parallel arguments in Gendron \& Bédard (2001) for accounting). However, as we demonstrated above, it seems that not only are finance academics in the main underachieving in producing research of value to the industry, they are also not generating evidence of use to policymakers in holding the industry to account for its shortcomings given the virtual absence of research on the ethics of finance or in critical finance. Since finance academics are apparently neither poacher nor gamekeeper, one may legitimately question their relevance for the functioning of financial markets.

\footnotetext{
${ }^{36}$ Figure as of 27 June, 2016. Not to be confused with REF2014 impact case studies, the ESRC's impact case studies 'highlight ESRC-funded research impact in various areas of society'.
} 
While finance research has been argued to have impacted upon practice in limited areas such as corporate governance and market behaviour in the early years of the development of finance theory, this influence has not continued or extended to practitioners' understanding of the implementation of sophisticated mathematical models or their underlying theoretical assumptions (Gippel, 2015b). We argue that this deficiency in communication between practitioners and academia is in part rooted in a lack of ethics incorporated into the subject matter of finance research leading to an uncritical and unreflective approach to the fields' underlying assumptions.

\section{Why has finance research contributed so little to the ethical behaviour of finance practitioners?}

Amoral or even immoral behaviour by financial market practitioners has been argued to have contributed to the financial crisis (see, for example, Santoro \& Strauss, 2012). Hence a discussion of how ethics could be incorporated into the decision-making and activities of bankers and other finance professionals ought to be an area where the academy could make a significant contribution. Yet, evidence suggests that the volume of ethics research published in finance has remained at a low constant rate since the late 1980s. Bernadi et al. (2008) examined the level of ethics research published in the 'top' 25 business ethics journals and 'top' 40 journals for accounting, finance and marketing between 1986 and 2005. Compared to accounting and marketing (approximately 50 articles per year) the quantity of ethics scholarship in finance has remained relatively constant between 1987 and 2005 at an average of seven co-author-adjusted articles per year. It is notable that marketing includes not only the Journal of Business Ethics in their 'top' 40 but also eight other journals in the list with a positive interest in ethics research. Compare this with finance where none of their 'top' 40 journals indicate such an interest. Within the finance area, none of the World Elite or $4 *$ journals according to the Association of Business School's Academic Journal Guide 2015 mention ethical or social issues in any context in their Aims and Scope, while the comparable figure is one third in the accounting field. ${ }^{37}$

This is not to conclude that there are no applications of ethical theory to the field of finance, in for example areas such as policy discussions of regulation and supervision and the rights and duties in financial contracts (Lai, 2014). A steady trickle of articles within ethics and finance journals has applied ethics concepts to the professional practice of finance. Utilitarian ethics is used to argue for the legalisation of insider trading (McGee, 2008) which is viewed as a balance between efficiency and fairness (Shefrin \& Statman, 1993) while high frequency trading is not seen as unfair from three ethics perspectives (Angel \& McCabe, 2013). How ethical standards can be applied in practice is seen in the work of Frederick \& Hoffman (1990) who make a case for restricting access to markets to protect the rights of at risk investors. Raines \& Leathers (1994) attribute the prominent role of financial derivative instruments to changes in social ethics which assume financial markets are the most efficient method of meeting the needs of a dynamic economy, in this way legitimising the gambling characteristics of these instruments.

However, few finance scholars consider the ethical implications of the field's theories and fundamental assumptions. ${ }^{38}$ In addition, such academics are unlikely to teach ethics and 'real-world' problems in undergraduate and MBA courses. Hence, students who follow these courses are therefore unlikely to benefit from early socialisation in ethics. Consequently, the uncritical investigation of the behavioural consequences of key finance theories by finance scholars is mirrored in practitioner use and is surely implicated in the neglect of ethics research in finance theory. Some exceptions include Le Montagner

\footnotetext{
${ }^{37} \mathrm{We}$ arrive at these figures following a manual search of the 'Aims and Scope' on the web site of each journal. Even in the lowest rated finance journals on the ABS list (2* and $1 *)$, around $20 \%$ mention an interest in social or ethical issues, whereas the figure is more than double that at $43 \%$ for comparable accounting journals.

${ }^{38}$ A notable exception is the recently published book by finance professor Maureen O'Hara, entitled 'Something for Nothing: Arbitrage and Ethics on Wall Street' (see O'Hara, 2016).
} 
(2006) who critiques the epistemic basis of finance theory and Horrigon (1987) who examines the normative consequences following from contemporary financial theories. His analysis of what he believed to be the five most influential concepts that have evolved in finance (the irrelevance theorem, efficient markets hypothesis, capital asset pricing model, options pricing model, and agency theory) provides a devastating critique of the field. In short, the behavioural consequences which would follow if all market participants acted in accordance with these concepts would result in a pervasive nihilism.

Both Blommestein (2006) and Boatright (2010) attribute the insignificant role of ethics in modern finance to the shift towards theory building and mathematical modelling inappropriate for the real world. It is this reification of abstract knowledge produced by quantitative finance theory which has been most implicated by commentators in financial market crashes since 1929 (Triana, 2009). More telling is the performative perspective of financial models on the relation of financial theory to practitioners' behaviour where theories that aim to describe real-world mechanisms in turn shape these financial practices (MacKenzie, 2001, 2009; MacKenzie \& Millo, 2003). For example, it has been shown that with the increasing popularity of the Black-Scholes model, practitioners' behaviour changed to fit the theory which was too abstracted from the reality it purported to represent (MacKenzie \& Millo, 2003).

It is argued that scientific revolutions, resulting in more successful models or those with ethical behaviour at their core, may be expected to be precipitated by junior academics who are less invested in the established orthodoxy (Kuhn, 1962). Is this likely to take place in finance? Doctoral programmes in the UK are increasingly moving towards the US model of one to two years' advanced courses, primarily in financial economics, plus an additional two to three years of undertaking original research. While a move to this framework might increase the methodological rigour of candidates' research, such an approach runs the danger of squeezing out the wider training in social sciences and research philosophy, opening minds to cross-disciplinary approaches and mixing with students of other specialisms, which has traditionally been the hallmark of a UK PhD. A similar argument can be made regarding the trend at several UK universities towards the organisation of training around consortia. ${ }^{39}$ While offering joint training of $\mathrm{PhD}$ candidates for several local universities is likely to increase the level of technical training of candidates and provides a more efficient use of resources, especially for smaller universities, such consortia - almost by definition - lead to further homogenisation of research agendas as $\mathrm{PhD}$ students attend the same types of training courses, at the same time learning the rules of the publication game.

Young scholars are quickly socialised into the process of producing formulaic research and are schooled in the career-risking dangers of attempting to break the mould. As Alvesson \& Gabriel (2013) note, the presence of 'meet the editor and get tips on how to publish in his or her journal' sessions that are frequently organised at leading conferences encourage conformity with established norms of writing style, methodology, and subject matter. ${ }^{40}$ While such homogenisation in the socialisation of young academics and its potentially harmful effects on the discipline, including a distortion of research innovation and an 'increasing collective intolerance towards alternative paths' (Pelger \& Grottke, 2015, p. 124), has been vocally criticised in the accounting academy (see also Prasad, 2015; Raineri, 2015;

\footnotetext{
${ }^{39}$ For example, the ESRC channel all of their PhD scholarship funding in the social sciences through 21 Doctoral Training Centres (DTCs), which are consortia of local universities, and through which training is often organised jointly.

40 Again, while these sessions might have their benefits, such as introducing new members to the academic standards of their fields, as unintended consequences they might reduce innovation and unconventional approaches but encourage conformity.
} 
Palea, 2017), to the best of our knowledge, similar discussions do not take place in finance journal outlets.

In addition, the over-production of $\mathrm{PhD}$ graduates at many business schools ${ }^{41}$ implies that lower ranked institutions are now increasingly staffed by academics who received their research training and socialisation at an 'elite' school, bringing their research focus and publication objectives with them and potentially further crowding out a more pluralistic approach to scholarship that the UK, and the European, academy have traditionally been known for (see also Pelger \& Grottke, 2015; and Palea, 2017, for a similar point regarding accounting research). While perhaps increasing 'quality', this has also helped a narrowly focused research agenda permeate through universities which might traditionally have had other objectives.

Both Ardalan (2005) and West (2015) attribute observed behaviour in financial markets with the functionalist paradigm dominant in mathematical finance. They note a homogeneity in both education and scholarship which coincides with similarities of practice between financial institutions which sustain the status quo. A lack of critical evaluation within 'top' finance journals and education in business schools is important because the growing number of graduates in financial mathematics are socialised into practices of quantitative finance that are rooted in the tradition of economic positivism. This increasing complexity of financial models is in inverse proportion to considerations of moral obligations by graduates who are rewarded for amoral behaviour. Thus, ironically, one point at which scholarly finance and 'the real world' are linked, is in the lack of a critical discourse and the virtual absence of a consideration of any ethical implications arising from the behaviour of financial market practitioners.

\section{Conceptualising 'Elite' Academic Finance and the Finance Industry in a Bourdieusian Framework.}

In the previous sections, we have presented evidence on the observable characteristics of finance as an academic field of scholarship by investigating the results of research evaluation exercises for UK business schools and analysing publication patterns in the 'top' finance journals. We have then linked these findings to the prior literature and additional numerical evidence to unmask the dominant research paradigms and incentive structures of finance scholars that help to explain these observable research characteristics. In particular, we have aimed to assess the relevance of the work produced by finance scholars for stakeholders outside of the finance academy. In this section, we combine our findings of the prior sections and place them into the conceptual framework of Bourdieu to better understand how the research paradigms and incentives have formed these observable characteristics of finance as a scholarly discipline and to shed further light on the apparent disconnect of finance scholarship from the practical applications of finance in the financial services industry.

Our general framework to conceptualise finance scholarship draws upon Bourdieu's concepts of 'fields', 'habitus', 'distinction' and on different forms of 'capital', and 'interests'. The framework is highly general and points to differing means by which fields can be constructed and sustained. However, as Malsch \& Gendron (2013) argue, Bourdieu's concept of habitus, or 'economic predispositions', is particularly helpful in making sense of the role of dominant traditions and paradigms in such fields and can help us to conceptualise the development of finance as a field of scholarship. Habitus can be defined

\footnotetext{
${ }^{41}$ For example, an article in the UK newspaper, The Independent ('What's up, Doc: Are too many students sailing through the British PhD?', R. Pugh, 13 May 2009), presents figures that the number of UK PhD students rose by a quarter in the decade to 2005 and laments the soaking up of first year research time with taught courses.
} 
as 'a system of lasting and transposable dispositions which, integrating past experiences, functions at every moment as a matrix of perceptions, appreciations and actions and makes possible the achievement of infinitely diversified talks" (Bourdieu \& Wacquant, 1992, p. 18).

Agents, that is to say, in this case finance scholars and practitioners in the financial services industry, create the spaces, or fields, which exist only through the agents that are found within them. Thus, fields are socially constructed by the actors that operate within them and they serve to provide a structure of the 'social spaces' which allows field-specific habitus to be formed, capital to be distributed among actors and values within the field to be determined (Lee \& Dunlap, 2014, p. 317). Hence, we can think of finance scholarship and the finance industry as two distinct 'fields' or 'social spaces' with different habitus and different ways of distributing capital and valuing its worth - and the observable characteristics and dynamics of the two fields are essentially the outcomes of different underlying predispositions and concepts of capital and values. Bourdieu's key idea is that economic life is largely the result of the encounter between actors with a special disposition (habitus) in the economic field, and that any transactions occurring within or between fields are deeply influenced by the nature of the field (Swedberg, 2011, p. 248).

'Distinction' between actors is structured around their stock of 'capital' which is a crucial resource in allowing actors to gain advantages within their field. Bourdieu (1997) broadly distinguishes between four different forms of capital: economic, cultural, financial and symbolic. For the field of finance scholarship, economic and cultural capital is derived from the legitimacy it receives from other fields (or respectable actors within its field) such as research evaluation groups (e.g. RAE2008 and REF2014). In addition, metrics such as citations and journal rankings serve as another source of cultural capital and hence, a higher number of citations or publications in a highly rated journal provide greater capital to actors. Together, these two mechanisms serve to explain the transition in submitted output to the RAE2008 and REF2014 as participating institutions (here finance departments) aimed to increase their evaluations by strategically submitting outputs that score highly on the relevant metrics. As 'impact' (for outside stakeholders) has been introduced as a new criterion, or metric, in REF2014 and will gain in importance for the overall evaluation in the next REF, it remains to be seen whether finance scholars will adopt their behaviour in order to increase their economic and cultural capital along this dimension.

Financial capital refers to the financial resources a field and its actors have at their disposal which for scholarly fields generally translates into fee income from students and research grant income from official funding bodies. While finance historically generated some of the largest student fee incomes across the business school - which enabled finance scholars to often demand a premium relative to its colleagues in other departments of the business school, its success in obtaining public research funding has been limited. Finally, symbolic capital comprises the resources available to an individual on the basis of honour, prestige or recognition (Bourdieu, 1997). Among finance scholars, symbolic capital mainly arises from publication in 'elite' journals and being associated with the 'elite'. The latter form of capital can explain the somewhat surprising trend in geographical coverage that we observed for the Review of Finance (Table 3). Despite being the only 'elite' journal associated with a non-US association and despite finance scholarship becoming more international over time, the share of its empirical studies that use US data as their sole source of data has increased and not decreased - most likely due to an attempt to emulate the other 'top' finance journals and hence increasing its symbolic capital.

The force attached to an agent depends on the volume and structure of the capital he or she possesses in its different forms. However, it is important to point out that capital is field-specific and does not necessarily allow advantages to be translated into other fields (see generally Bourdieu, 1997). Fields are thus characterised by specific combinations of the capital of their members, where certain types of 
capital are particularly valued. By possessing higher symbolic capital, an individual distances himself from his peers becoming more successful in his social trajectory and also economic advancement - and through these distances the structure of the 'field' is formed. Hence, actors in different sectors or fields will aim to increase the capital as it is defined and regarded most valuable and relevant in their field. If we again consider finance scholars and practitioners in the financial services industry to have different field-specific interpretations of capital, this can serve to explain the apparent disconnect between the two fields and why finance research targeted at increasing scholars' capital within their field does not necessarily translate into outputs that increase the capital regarded as valuable to finance practitioners.

From this perspective, individuals are characterised with thought patterns, established through long processes of inculcation during their lifetimes and in particular within their field, including professional education and apprenticeship, which predispose them to act and react in certain ways in certain situations. Socialisation, therefore, plays a central role in forming one's habitus and helps to explain the observable characteristics of a field and the corresponding behaviour of its actors. For instance, the type of research produced and published in finance (e.g. concentration on studies based on US datasets, as documented in Tables 6 and 7) can be attributed to the socialisation process of finance scholars through their doctoral studies as discussed in the prior sections and their interpretation of the symbolic capital that this research entails.

The norms that have become established in many universities to favour 'elite' journal publication over other forms of scholarly contribution are reinforced by incentive structures surrounding pay and promotion (Willmott, 1995; Pelger \& Grottke, 2015; Netter et al., 2018). Performance measurement has become objectified whereby academics are increasingly required to demonstrate that they have achieved certain key performance indicators (Gendron, 2008; Humphrey \& Gendron, 2015), principal among these is 'top' journal publication. Hence, finance scholarship serves as an example of one of Bourdieu's main points, namely how the organisation of various fields ultimately allows for domination (of particular accepted practices), with the legitimation of power. ${ }^{42}$ By following an elitist habitus and acting with such deference to the 'elite' journals, the characteristics of the research published there are elevated to the status of constituting the only appropriate topics and methodologies to be used for scholarly enquiry in finance more broadly and in this way 'elite' journals implicitly control the agendas and approaches of a much wider group of researchers who will eventually publish in lower rated journals (or not at all). There is a danger that those who refuse to subscribe to the 'elite' publishing agenda will be punished via marginalisation within the department and possibly higher teaching or administrative loads (Alvesson \& Sandberg, 2013, p. 141).

A further Bourdieusian concept of relevance in order to understand how the two 'fields' of academic finance and the financial services industry co-exist is what Bourdieu terms 'interest'. For 'Interest is to 'be there,' to participate, to admit that the game is worth playing and that the stakes that are created in and through this fact are worth pursuing; it is to recognize the game and to recognize its stakes' (Bourdieu \& Wacquant 1992, pp. 115-17). We argue that 'interest' between the practice of finance by financial services practitioners and 'elite' academic finance is driven by the antithesis of 'interest' or illusio as both follow different rules of the 'game' and regard different objects worthy of pursuit while both wish to sustain the status quo which conforms to the habitus of their specific 'field' ${ }^{43}$ To illustrate, scholars form their identities largely around the specific sub-disciplines that they work in and the

\footnotetext{
42 The central work for distilling Bourdieu's approach to stratification is that of distinction (Bourdieu, 1984).

${ }^{43}$ This ironic link in the mutual disinterest between academics and practitioners has also been noted by Fogarty (2018, p. 55) who characterises the relationship between the accounting profession and academia as a 'symbiotic relationship ... between practitioners who do not really want academic contributions and a group of academics who cannot provide practice-based contributions'.
} 
methodological approaches they adopt (Gulati, 2007, p. 778). Researchers in business schools are socialised into an organisational culture where identities are 'framed within the stream of research' rather than 'organisational problems and a question that we want to understand and answer' (Vermeulen, 2007, p. 754). Hence 'usefulness' in the 'elite' journals, and hence in the scholarly field of finance, is defined according to how much the work advances an intellectual debate or understanding of a phenomenon rather than whether those outside the academy could draw on the work to influence policy or practice. As a consequence, 'interest' as considered by finance scholars does not involve the dimensions of 'interest' that practitioners or governments consider worth pursuing, such as producing practically relevant work that can affect market behaviour, policies and regulations. Put differently, finance researchers derive their identities, their 'market values', and their personal sense of worth not from the topics they work on or what they write, but rather from the journals they publish in (Willmott, 2011a).

\section{Discussion and conclusions}

Viewed from the perspective of its size and intellectual 'quality' (at least as measured by research evaluation exercises), academic finance research is flourishing and has come to be considered an important sub-field within Business School research (Horrigan, 1987). Over the past two decades the sub-field emerged from the shadows of its closest cognate disciplines - accounting and economics - to take on an identity and a research agenda of its own. In this study, we have presented evidence, primarily from the UK, that despite its scholarly vitality, finance research is not making a commensurate contribution to policy or practice, and nor is it producing thought leadership that could influence the ethical behaviour of financial market practitioners.

In particular, the findings of our quantitative analyses point to a lack of diversity in finance research with respect to the methodological approaches used and its geographical coverage. We find that finance publications rely predominantly on a positivist approach characterised by sophisticated mathematical models and quantitative empirical methods while the use of alternative approaches such as qualitative studies and interdisciplinary research is almost absent in the scholarly publications present in the 'top' finance journals. The use of sophisticated techniques, however, is argued to reduce the amount of highimpact research being generated in management (Alvesson \& Sandberg, 2013, p. 134). As such, we argue that the finance literature has boxed itself into an intellectual corner where highly mathematical research is considered superior (McGoun \& Zielonka, 2006). Yet while the models are often sophisticated and cannot be solved analytically, they still represent such vast abstractions from reality that they often have little practical value. Even a slight loosening of an assumption can have a profound effect on the results.

While our results suggest that the authors of scholarly finance publications are increasingly drawn from outside of the US, the geographical coverage of the research itself remains limited to a relatively small set of data sources with a dominant US focus, even in cases where the journals are edited outside of the US or the authors are from non-US academic institutions. Traditionally, non-US journals have published work on a broader range of topics and using a greater variety of methodologies (Raffournier \& Schatt, 2010), but this is in danger of becoming lost as the objectives and approaches of the US and European 'elites' (Lukka \& Kasanen, 1996; Palea, 2017) become indistinguishable.

Moreover, we argue that it is also possible to view elitism in finance research as an indirect cause of its lack of practical relevance and a disconnection of finance academics from finance practitioners. This is in line with Whitley's observation (1986, p. 174) of the 'strong boundaries between academically significant work and everyday knowledge' that emerged as the subject became increasingly dominated 
by ideas and formal models drawn directly from neoclassical economics from the 1960s onwards. On the one hand, the majority of finance academics do not seem to be interested in producing practitioneroriented and/or policy-focused research. As Markides (2007, p. 764) notes, 'the sets of skills, mindsets, and attitudes that are needed to conduct rigorous academic research are fundamentally different from the set of skills, values, and attributes needed to conduct managerial research' and 'a researcher who tries to simultaneously offer two different, inconsistent kinds of value runs the risk of damaging her or his existing image and reputation'. On the other hand, it appears that practitioners seem mostly uninterested in working with scholars to gain insights into the latest research findings. This is surprising, as many of those practising in the financial markets have studied finance as an academic subject at universities, and in that sense they will be aware of the theories and concepts that they were taught.

Drawing on Bourdieu's concept of 'habitus', it is ironic that both scholars and practitioners of finance are behaving in the same way, existing within their own habitus and building their own stock of capital. They pursue narrow agendas that create wealth and prestige within their own spheres, ignoring any ethical considerations relating to a wider sense of purpose or responsibility to society, and using finance theory as a justification for their actions. In this sense, without knowing, they are deeply connected even if not at an operational level. ${ }^{44}$

As a consequence of the divisions between academic and practitioner finance, and notwithstanding the vast resources devoted to the sub-field (higher salaries, computing power, expensive databases) and its intellectual strength, finance is punching below its weight in failing to address real-world problems relative to other sub-fields in business and management. Scholars in finance, like those in other fields, still have an enviable degree of latitude to establish their own research agendas and to choose their own topics of investigation and their own approaches, despite an increasingly managerial culture in business schools and the growing twin external pressures of the REF and student satisfaction ratings (the $\mathrm{TEF}^{45}$ ) in UK universities. With this freedom should come responsibility - a collective responsibility, ethically informed, to create knowledge that benefits the economy and society or scholars outside the sub-field. By electing to work separately from the rest of the academy, and largely shutting themselves off from the real world, finance specialists have placed themselves in a perilous position ethically and epistemically. This can be reversed by a reflexive commitment to reappraise conventional professional legitimacy in academic finance and to adopt an academic identity based on integrity and a pursuit of the common good.

Changing research agendas in academic finance is not an easy proposition in the face of such longestablished academic conventions around research methodology and publishing, and given the incentive and reward structures that exist, but we now discuss several potential remedies for the current situation. In particular, we believe that a multi-faceted approach including simultaneous change on many fronts and involving a plethora of stakeholders is most likely to yield success. In the following, we will discuss our proposals targeting the journal publishing landscape, the research culture among finance academics, the incentive and reward systems in universities, the training of new finance scholars, and the promotion of explicit collaborations between finance industry and academy.

Firstly, there is a pressing need for a re-evaluation of ideas in the academic finance field. Weaver (2011), commenting on an article by Ryan et al., (2010), outlines the necessity for understanding the

\footnotetext{
${ }^{44}$ We thank an anonymous referee for providing this insight.

${ }^{45}$ The 'TEF' is the Teaching Excellence Framework, a new nationwide evaluation of various aspects of taught programmes in the UK which seeks to evaluate their 'quality' in UK universities, and which was introduced for the first time in 2017.
} 
institutionalising of conventions in financial practice, what resources sustain them, and which behaviours and social interactions keep them stable. Moreover, how do academic theories legitimate or reflect current financial practice? As a way of addressing these challenges, West (2015) suggests finance theory needs to elevate critical thought to the same standard as found in other professions such as medicine. In particular, adopting a critical frame with regards to the epistemic structure of the field (Le Montagner, 2006) and delegitimising the practice of conflating theory with hypothesis (Gippel, 2015b). To date there is no well-established critical journal within the finance discipline, ${ }^{46}$ in contrast to most other business sub-fields. In accounting, for example, there is a willingness in some highly rated scholarly journals to publish interpretivist and critical articles as well as those employing empirical analysis of data in the positivist tradition (Gendron \& Smith-Lacroix, 2015, p. 97). A critical lens involves broadening the established boundaries of research (Gippel, 2015a) to include insights from the social sciences and applied ethics. In particular, the normative evaluation of academic finance ideas could borrow from related research in fields such as accountancy and from work in behavioural economics and decision theory. In the UK, an increased level of ethics research would be assisted by the establishment of a discipline-specific ethics journal or supporting conferences devoted exclusively to ethics research (Bernadi et al., 2008).

Secondly, while these are potentially important means to broaden the approach to financial research, and potentially to find a wider source of angles whereby financial academia may impact on practitioners and put the sector under a more critical spotlight, it is also the case that the 'elite' journals themselves should have a central role to play. Indeed, where the 'elite' outlets provide legitimacy to a narrow research agenda, it is within their power to provide positive contributions to the field by, for example, embracing work that differs methodologically, that highlights different theoretical developments, or that brings new insights from other fields such as psychology or history more fully than is currently the case. For instance, Endenich \& Trapp (2018) in their analysis of the scholarly profiles of the editorial teams of the Contemporary Accounting Research (CAR, the journal of the Canadian Accounting Association) and The Accounting Review (TAR, the journal of the American Accounting Association), find that editors can send strong signals to the research community through the makeup and appointment of their editorial team. The authors argue that the increased quantitative empirical focus of TAR's editorial team signals to the research community that such research is the 'acceptable' way of doing research and hence leads to increased submissions of quantitative empirical studies, as empirically documented by the authors. In contrast, Endenich \& Trapp associate the growing share of field and case studies among CAR's publication to the appointment of field and case researchers to CAR's editorial team. ${ }^{47}$ As such, they characterise journal editors not only as 'gate keepers' but attribute them with the 'construction of the accounting knowledge production system' (Endenich \& Trapp, 2018, p. 20). As Salterio (2018, p. 82) states, such measures are particularly powerful as the status of CAR's editors as 'mainstream elite' members due to their education at 'elite' institutions 'made it possible to facilitate and legitimize change as they were inside the 'club". However, while change from within the 'elite' would certainly legitimise a more pluralistic approach, senior researchers may have a habitus that is

\footnotetext{
${ }^{46}$ A potential exception is the Critical Finance Review. However, an examination of the contents of the journal suggests that the contents are within the mainstream finance area and would not be regarded as critical in the sense that scholars in other fields understand the term. Rather, the journal uses the word as it relates to 'important'.

${ }^{47}$ In his commentary to Endenich \& Trapp's (2018) study, Salterio (2018, p. 80), the past editor in-chief of the $C A R$ and co-responsible for its diversification strategy, confirms that they 'explicitly signalled that openness through editorial appointments', among various other methods. In contrast, Kachelmeier (2018, p. 64), past editor of $T A R$, argues that the composition of $T A R$ 's editorial team reflects the past submission patterns to the journal and that 'he did not attempt to dictate to the community what he wanted to see'.
} 
quite supportive of domination and status quo derived from the benefits of forming part of this group, and we see important roles for external pressure and continued scrutiny to be applied.

Thirdly and ironically, as we documented in section 4, much of the most critical, novel, and relevant research relating to finance is currently being published in journals outside of the finance 'elite', such as Critical Perspectives on Accounting. The latter is not only outside of this 'elite', but even outside of what would traditionally be classified as finance outlets. These alternative finance journals should be given greater priority as first picks by researchers when deciding where to publish their most promising work rather than second best choices. Such a strategy could be used by scholars in the area to gradually raise the legitimacy and quality of these alternative journals instead of devoting so much energy to carrying out rigorous but quite trivial research projects to be submitted to the 'top' journals. ${ }^{48}$

Fourthly, in terms of the training which those new to the profession receive, we need to ensure that $\mathrm{PhD}$ programmes cover a wider range of material in methodologies than purely financial economics and econometrics, and that junior academics are imbued with the skills to be able to form their own evaluations of research rather than relying on a ranking list. Humphrey \& Gendron (2015, p. 62) argue that there is a need for a 're-socialisation' of academics - in particular focusing on junior faculty regarding the importance of making up their own minds about the 'quality' of a piece of research (see also Callen, 2015; Pelger \& Grottke, 2015; Prasad, 2015; Raineri, 2015; Palea, 2017; Fogarty, 2018; and Roberts, 2018; who raise similar demands regarding doctoral programmes in accounting departments). Hence, we argue for the pursuit of a broad-based foundation in academic finance within $\mathrm{PhD}$ programmes, informing a plurality of approaches where none is favoured over the other at the outset but where each is given a potential role in forming judgements. This suggestion echoes the recommendations of the Business and Management REF2014 sub-panel, outlined in its Subject Overview report, commenting that:

'the diversity of UK research, sometimes answering different kinds of questions and, where necessary, drawing on UK and international data, remains a strength of the UK academy which is valued internationally and should continue to be nurtured and respected.' (p. 60).

Fifthly, Zingales (2015, p. 1329) advocates that finance academics should engage more in policy-related work, which he argues suffers from a lower status within the profession than more theoretical work. Similarly, Bennis \& O'Toole (2005) have argued that management schools have emphasised technical research that is not relevant for practical managers. Hence rewards for relevance are weak. As a consequence, there is currently a systemic disjoint between the needs of government and industry on the one hand and the kinds of research produced by academics on the other, and there are dangers that this gap will grow as journal rating lists become more engrained in driving the performance measurement of academics (Willmott, 2011a; 2011b). Hence, a key policy response would be to ensure that the incentive structures of scholars are aligned to producing relevant as well as intellectually 'high quality' research. The predicted increase in the weight of impact in the next REF and the growing importance that universities in the UK are attaching to this activity should support such a change of focus. This could be further enhanced if the spirit of the REF impact agenda is extended to other facets of academic life, such as being a more prominent consideration in determining research funding and on promotions committees, and that credit is given to scholars who engage with policymakers and practitioners, with the latter being given more involvement in university committee decisions. As Vermeulen (2007, p. 758) notes, 'the academic system does not generally value managerial relevance, particularly when it comes to tenure decisions'. Hence, one way to elevate managerial relevance among

${ }^{48}$ We thank the Editor, Yves Gendron, for this suggestion. 
scholars would be by conditioning probation and promotion decisions on wider scholarly contributions rather than only on the ratings of the journals a researcher has published in.

The paradox is that the corporatisation of academic life is often considered a serious problem yet scholarly finance, almost entirely free from outside world constraints and left to do its own thing, has chosen to turn inwards entirely to produce huge swathes of research with almost no practical value whatsoever. Perhaps the introduction of explicit incentive structures (as a form of managerial control) would not be a bad thing if they were designed to encourage finance scholars to reach out to other disciplines or to their user communities. The impact aspect of the REF2014 was initially met with scepticism and even disgust by the academy, but it may have modified the mind-sets of researchers by incentivising at least some of them to produce research that is useful to a wider group of stakeholders. Ironically, the UK has a strong tradition of doing this but it is in danger of becoming lost. It is crucial that finance researchers come to consider their identities as scholars and their sense of self-worth to derive from impactful contributions as well as publications in 'elite' journals. While this modified incentive structure could engender a danger that there would be a bifurcation of academic efforts into those who produce 'elite' journal publications and those who do 'impact work', arguably this would still be better than the current situation where very few finance researchers at all are engaged in the latter.

Sixthly, as a practical measure to encourage impactful collaborations, Rooney et al. (2008) argue for the creation of robust knowledge innovation networks between practitioners and academics. These networks should engage in communicative relationships at the level of practical knowledge, undertaking research of direct relevance to end users and involving them in the research process. For instance, innovation in finance could focus upon stewardship in the pursuit of community goals. There is a need to encourage the industry to reflect on their purpose in society but this drive is not presently coming from the academy. We believe that it would be fruitful for scholars, regulators and practitioners to establish joint conferences, which could be supported by some of the alternative finance journals, where common research agendas could be discussed and results that are rigorous but rooted in real world problems could be presented. In addition, it would be valuable for practitioners to be invited to shape doctoral research agendas, for instance by being involved in $\mathrm{PhD}$ programmes and advising $\mathrm{PhD}$ students on the practitioner perspective on research topics. This would ensure that emerging scholars were given a steer towards practically relevant topics and the needs of the financial services sector right at the beginning of their academic careers, and would also allow a flow of knowledge from the academy to the industry on the latest scholarly thinking and approaches to a particular challenge.

Equally important to ensure that finance research addresses questions relevant to the finance practice is that industry practice also directly informs academics' research agendas. To further this goal, scholars should be encouraged to make greater use of field research and qualitative approaches, where they observe the context in which financial decisions are made and transactions take place and directly interact with finance practitioners, rather than relying purely on standardised secondary datasets and hence being removed from finance practice. ${ }^{49}$ This is likely to yield a much wider range of new insights which could inspire the development of novel ideas and theories. It is important that such a new research stream involves the construction of concepts and theories that are formally connected to existing finance theory in some way, so that its key tenets can be challenged directly from within. In this way, academic

\footnotetext{
${ }^{49}$ Guidance on conducting qualitative research and field research can be found in Power \& Gendron (2015), Malsch \& Salterio (2016) and Ahrens \& Chapman (2006). While the first two studies focus on qualitative research in auditing and the latter addresses qualitative field research in management accounting, their insights can be easily transferred to a finance setting.
} 
finance can draw knowledge and data from the 'real world' to refine and improve theories whilst explicitly recognising the context in which financial decisions and transactions take place. Hence, we argue for a more pluralistic approach to finance research which would not only promote a broader, more relevant, and inclusive research agenda (Roberts, 2018), but also a more holistic understanding of the underlying phenomena given the inherent limitations of different methodological approaches.

Furthermore, in order to encourage practitioners to make use of their research as well as to stimulate interdisciplinary research, academics need to 'demystify' their findings and write them in a language that will resonate with wider stakeholders. Finance research is laced with technical terminology that acts to constrain opportunities for practitioners and scholars from other fields to make contributions that are acceptable to 'the elite' and fit within its paradigm. This observation is in parallel to the 'language barrier' that has been documented in accounting research, both between accounting scholars and practitioners as well as between accounting scholars from different methodological camps (interpretivist/qualitative versus positivist/archival) (Kachelmeier, 2018), and which may prevent auditors from making more use of academic outputs (see Sullivan, 1993). This barrier may also discourage engagement between scholars using different methodological approaches and relying on different research paradigms in conducting their research. If finance research aims to be used by and benefit wider groups of the society, a less technical and a more transparent language could support this goal.

Finally, some commentators have suggested that, in addition to wholesale changes to finance theory, there should also be modifications in the way that it is taught (see, for example, Shiller, 2010). Fabozzi et al.'s (2014) proposal for changes to finance Masters programmes include the extension or addition of material on: macroeconomics, financial history, behavioural finance, non-Gaussian statistics, risk management and ethics. Rather than bolting ethics onto a programme, it should be integrated into core finance topics (Danielson \& Lipton, 2010). There is also the suggestion that finance education should be more introspective and more heterodox in contrast to its current narrow focus (Lakshmi, 2016). West (2015) suggests tailoring ethics courses to professional practice on instances where ethical questions arise and the principles which might be utilised to answer them to protect stakeholders from the costs of unethical behaviour. This is an area where finance academics could make a significant contribution to professional practice.

In conclusion, we argue that the focus on 'elite' publishing in finance and the implicit marginalisation of other journals downplays the impact and potential for innovation of finance research. To initiate change, it is imperative to encourage finance scholars to develop research agendas which are critically challenging but potentially addressing different questions using a plurality of approaches. As such, we need to foster a culture where the world's 'best' researchers feel that working on a wider range of issues and studying non-US markets will potentially result in work publishable in well-recognised journals rather than being a slight on their reputations which will jeopardise their careers and ultimately their salaries. This would provide a possible route that would allow us, probably through the work of emerging new scholars, to address the issues that are really of concern to the global economy and society. 


\section{References}

Ahrens, T., \& Chapman, C. S. (2006). Doing qualitative field research in management accounting: Positioning data to contribute to theory. Accounting, Organizations and Society, 31(8), 819-841.

Alexander, J. C., \& Mabry, R. H. (1994). Relative significance of journals, authors, and articles cited in financial research. Journal of Finance, 49(2), 697-712.

Alvesson, M., \& Gabriel, Y. (2013). Beyond formulaic research: in praise of greater diversity in organisational research and publications. Academy of Management Learning and Education, 12(2), 245-263.

Angel, J. J., \& McCabe, D. (2013). Fairness in financial markets: the case of high frequency trading. Journal of Business Ethics, 112, 585-595.

Ardalan, K. (2005). Mathematics and academic finance: the role of paradigms. International Journal of Social Economics, 32(4), 276-290.

Ardalan, K. (2008). On the Role of Paradigms in Finance. Aldershot: Ashgate.

Ashton, D., Beattie, V., Broadbent, J., Brooks, C., Draper, P., Ezzamel, M., Gwilliam, D., Hodgkinson, R., Hoskin, K., Pope, P., \& Stark, A. (2009). British research in accounting and finance (2001-2007): the 2008 research assessment exercise. British Accounting Review, 41(4), 199-207.

Association of Business Schools (2010). Academic Journal Quality Guide. London, Chartered Association of Business School.

Balatbat, M, Taylor, S., \& Walter, T. (2004). Corporate governance, insider ownership and operating performance of Australian initial public offerings. Accounting and Finance, 44, 299-328.

Beattie, V. (2005). Moving the financial accounting research front forward: the UK contribution. British Accounting Review, 37(1), 85-114.

Beattie, V., \& Goodacre, A. (2004). Publishing patterns within the UK accounting and finance academic community. British Accounting Review, 36(1), 7-44.

Beattie, V., \& Goodacre, A. (2012). Publication records of accounting and finance faculty promoted to professor: evidence from the UK. Accounting and Business Research, 42(2), 197-231.

Bell, T. B., \& Wright, A. M. (1995). Summary, Obstacles, and Future Directions. In T. B. Bell, \& A. M. Wright (Eds.), Auditing Practice, Research, and Education: A Productive Collaboration (pp. 174182). New York: American Institute of Certified Public Accountants.

Bennis, W., \& O’Toole, J. (2005). How business schools lost their way. Harvard Business Review Online, 1-10.

Bernadi, R. A., Melton, M. R., Roberts, S. D., \& Bean, D. F. (2008). Fostering ethics research: An analysis of the accounting, finance and marketing disciplines. Journal of Business Ethics, 82, 157-170.

Bettner, M. S., Robinson, C., \& McGoun, E. (1994). The case for qualitative research in finance. International Review of Financial Analysis, 3(1), 1-18. 
Bornmann, L. (2013). What is societal impact of research and how can it be assessed? A literature survey. Journal of the American Society for Information Science and Technology, 64(2), 217-233.

Blommestein, H. J. (2006). Why is ethics not part of modern economics and finance? A Historical Perspective. Finance \& Bien Commun, 24, 54-64.

Boatright, J. R. (2010). Ethics in finance. In J. R. Boatright (Ed.), Finance Ethics: Critical Issues in Theory and Practice (pp. 1-19). Hoboken: John Wiley \& Sons Inc.

Bourdieu, P. (1984). Distinction: A social critique of the judgement of taste. Cambridge, MA: Harvard University Press.

Bourdieu, P. (1997). 'The Forms of Capital'. In A. H. Halsey, H. Lauder, P. Brown and A. S. Wells (Eds.), Education: Culture, Economy, Society (pp. 46-58). Oxford: Oxford University Press.

Bourdieu P., \& Wacquant, L. J. D. (1992). An invitation to reflexive sociology. Chicago, Illinois: University of Chicago Press.

Brooks, C., Fenton, E. M., \& Walker, J. T. (2014). Gender and the evaluation of research. Research Policy, 43(6), 990-1001.

Brooks, C., \& Schopohl, L. (2018). Topics and trends in finance research: who is published, who publishes it and what gets cited. British Accounting Review, In Press.

Burchell, S., Clubb, C., Hopwood, A., Hughes, J., \& Nahapiet, J. (1980). The roles of accounting in organizations and society. Accounting, Organizations and Society, 5(1), 5-27.

Cabell, D. W. E. (2004). Directory of Publishing Opportunities in Economics and Finance, $9^{\text {th }}$ Edition, Beaumont, Texas: Cabell Publishing Co.

Callen, J. L. (2015). A selective critical review of financial accounting research. Critical Perspectives on Accounting, 26, 157-167.

Carter, R. B., \& Van Auken, H. E. (1990). Security analysis and portfolio management: a survey and analysis. Journal of Portfolio Management, 16(3), 81-5.

Chen, L., Danbolt, J., \& Holland, J. (2014). Rethinking bank business models: the role of intangibles Accounting, Auditing and Accountability Journal, 27(3), 563-589.

Colander, D., Goldberg, M., Haas, A., Juselius, K., Kirman, A., Lux, T., \& Sloth, B. (2009). The Financial Crisis and the Systemic Failure of the Economics Profession, Critical Review, 21(2-3), 249267.

Coleman, L. (2014). Why finance theory fails to survive contact with the real world: A fund manager perspective. Critical Perspectives on Accounting, 25, 226-236.

Coleman, L. (2015). Facing up to fund managers: an exploratory field study of how institutional investors make decisions. Qualitative Research in Financial Markets, 7(2), 111-135.

Collini, S., (2012). What are universities for? London: Penguin.

Daneke, G. A., \& Sager, A. (2015). Ghoshal's ghost: Financialization and the end of management theory. Philosophy of Management, 14, 29-45. 
Danielson, M. G., \& Lipton, A. F (2010). Ethics and the introductory finance course. Journal of Business Ethics Education, 7, 85-102.

Das, J., Do, Q.-T., Shaines, K., \& Srikant, S. (2013). U.S. and them: the geography of academic research. Journal of Development Economics, 105, 112-130.

Dore, R. (2008). Financialization and the global economy. Industrial and Corporate Change, 17(6), 1097-1112.

Drachter, K., Kempf, A., \& Wagner, M. (2007). Decision processes in German mutual fund companies: evidence from a telephone survey. International Journal of Managerial Finance, 3(3), 49-69.

Durand, D. (1968). State of the finance field further comment. Journal of Finance, 23(5), 848-852.

Endenich, C., \& Trapp, R. (2018). Signaling effects of scholarly profiles - The editorial teams of North American accounting association journals. Critical Perspectives on Accounting, 51, 4-23.

Fabozzi, F., Focardi, S. M., \& Jonas, C. (2014). Investment management: a science to teach or an art to learn. CFA Institute Research Report.

Fogarty, T. J. (2018). Avoiding self-deception in the study of academic accounting: A commentary about and beyond Endenich and Trapp's article. Critical Perspectives on Accounting, 51, 52-55.

Fox, J., \& Sklar, A. (2009). The myth of the rational market: A history of risk, reward, and delusion on Wall Street. New York: Harper Business.

Frankfurter, G., \& McGoun, E. (1999). Ideology and the theory of financial economics. Journal of Economic Behavior and Organization, 39, 159-177.

Frederick, R. E., \& Hoffman, W. M. (1990). The individual investor in securities markets: An ethical analysis. Journal of Business Ethics, 9(7), 579-589.

Frino, A., Jones, S., \& Wong, J. (2007). Market behaviour around bankruptcy announcements: Evidence from the Australian stock exchange. Accounting and Finance, 47, 713-730.

Gendron, Y. (2008). Constituting the academic performer: The spectre of superficiality and stagnation in academia. European Accounting Review, 17(1), 97-127.

Gendron, Y., \& Bédard, J. (2001). Academic auditing research: an exploratory investigation into its usefulness. Critical Perspectives on Accounting, 12, 339-368.

Gendron, Y., \& Smith-Lacroix, J.-H. (2015). The global financial crisis: Essay on the possibility of substantive change in the discipline of finance. Critical Perspectives on Accounting, 30, 83-101.

Geuna, A., \& Martin, B.R. (2003). University research evaluation and funding: An international comparison. Minerva, 41(4), 277-304.

Gillan, S. L., Hartzell, J. C., Koch, A., \& Starks, L. T. (2018). Getting the Incentives Right: Backfilling and Biases in Executive Compensation Data. Review of Financial Studies, 31(4), 14601498.

Gillies, D. (2012). Economics and research assessment systems. Economic Thought, 1, 23-47.

Gippel, J. (2013). A revolution in finance? Australian Journal of Management, 38, 125-146. 
Gippel, J. (2015a). Masters of the Universe: What top finance academics say about the 'state of the field'. Australian Journal of Management, 40(3), 538-556.

Gippel, J. (2015b). The Masters of Finance: Ideas from the field. Australian Journal of Management, 40(3), 557-561.

Gulati, R. (2007). Tent poles, tribalism, and boundary spanning: the rigor-relevance debate in management research. Academy of Management Journal, 50(4), 775-782.

Hellman, N. (1996). What causes investor action? European Accounting Review, 5(4), 671-691.

Hicks, D. (2012). Performance-based university research funding systems. Research Policy, 41, 251261.

Hirshleifer, D. (2015). Editorial: Cosmetic surgery in the academic review process, Review of Financial Studies, 28(3), 638-649.

Holland, J. (1994). Bank lending relationships and the complex nature of bank-corporate relations. Journal of Business Finance and Accounting, 21(3), 367-393.

Holland, J. (2006). Fund management, intellectual capital, intangibles and private disclosure. Managerial Finance, 32(4), 277-316.

Holland, J. (2010). Banks, knowledge and crisis: a case of knowledge and learning failure. Journal of Financial Regulation and Compliance, 18(2), 87-106.

Holland, J. (2016). A behavioural theory of the fund management firm. European Journal of Finance, 22(11), 1004-1039.

Holland, J., \& Doran, P. (2010). Financial institutions, private acquisition of corporate information, and fund management. European Journal of Finance, 4(2), 129-155.

Holland, J., Henningsson, J., Johanson, U., Koga, C., \& Sakakibara, S. (2012). Use of IC information in Japanese financial firms. Journal of Intellectual Capital, 13(4), 562-581.

Horrigan, J. O. (1987). The ethics of the new finance. Journal of Business Ethics, 6, 97-110.

Humphrey, C. (2008). Auditing research: A review across the disciplinary divide. Accounting, Auditing \& Accountability Journal, 21(2), 170-203.

Humphrey, C., \& Gendron, Y. (2015). What is going on? The sustainability of accounting academia. Critical Perspectives on Accounting, 26, 47-66.

Judge, T. A., Cable, D. M., Colbert, A. E., \& Rynes, S. L. (2007). What causes a management article to be cited: article, author or journal. Academy of Management Journal, 50(3), 491-506.

Kachelmeier, S. J. (2018). Do journals signal or reflect? An alternative perspective on editorial board composition. Critical Perspectives on Accounting, 51, 62-69. 
Kay, J. (2012). The map is not the territory: an essay on the state of economics. In D. Coyle (Ed.) What's the use of Economics? Teaching the Dismal Science after the Crisis. London: London Publishing Partnership.

Keasey, K., \& Hudson, R. (2007). Finance theory: a house without windows. Critical Perspectives on Accounting, 18, 932-951.

Kindleberger, C. P., \& Aliber, R. Z. (2005). Manias, Panics and Crashes: History of Financial Crises, $5^{\text {th }}$ edition, New Jersey: John Wiley and Sons.

Krugman, P. (2009). How did economists get it so wrong? The New York Times, 2 September. Available at: http://www.nytimes.com/2009/09/06/magazine/06Economic-t.html?_r=2 (accessed 17/10/2016).

Kuhn, T. S. (1962). The Structure of Scientific Revolutions. Chicago: University of Chicago Press.

Lai, J. (2014). Accountability and the enforcement of ethical values in finance: Insights from Islamic finance. Australian Journal of Public Administration, 73(4), 437-449.

Lakshmi, G. (2016). Gekko and black swans: Finance theory in UK undergraduate curricula. Critical Perspectives on Accounting, forthcoming.

Le Montagner, H. R. (2006). Financial theory on ethics: The reasons for silence. Finance \& the Common Good/Bien Commun., 24, 20-27.

Lee, T. (1995). Shaping the US academic accounting research profession: The American Accounting Association and the social construction of a professional elite. Critical Perspectives on Accounting, 6(3), 241-261.

Lee, K. J., \& Dunlap, R. (2014). The implication of Bourdieu's theory of practice for leisure studies. Leisure Sciences, 36(3), 314-323.

Ljungqvist, A., Malloy, C., \& Marston, F. (2009). Rewriting history. Journal of Finance, 64(4), 19351960.

Lo, A. W. (2011). Adaptive markets and the New World Order. Available at SSRN: https://ssrn.com/abstract=1977721.

Lord, M. (2014). Smaller university endowments: team characteristics, portfolio composition and performance. Qualitative Research in Financial Markets, 6(1), 4-32.

Macey, J. R., \& O'Hara, M. (2009). Regulation and scholarship: constant companions or occasional bedfellows? Yale Journal on Regulation, 26(1), 89-116.

MacKenzie, D. (2001). The big, bad wolf and the rational market: Portfolio insurance, the 1987 crash and the performativity of economics. Economics and Society, 33(3), 303-334.

MacKenzie, D. (2009). Material markets: How economic agents are constructed. Oxford: Oxford University Press.

MacKenzie, D., \& Millo, Y. (2003). Constructing a market, performing theory: The historical sociology of a financial derivatives exchange. American Journal of Sociology, 109(1), 107 -145. 
Malsch, B., \& Gendron, Y. (2013). Re-theorizing change: Institutional experimentation and the struggle for domination in the field of public accounting. Journal of Management Studies, 50(5), 870-899.

Malsch, B., \& Salterio, S. E. (2016). Doing good field research: Assessing the quality of audit field research. Auditing: A Journal of Practice \& Theory, 35(1), 1-22.

Markides, C. (2007). In search of ambidextrous professors. Academy of Management Journal, 50(4), 762-768.

McGee, R. W. (2008). Applying ethics to insider trading. Journal of Business Ethics, 77(2), 205-217.

McGoun, E. (1992). On knowledge of finance. International Review of Financial Analysis, 1(3), 161177.

McGoun, E. (2003). Financial models as metaphors. International Review of Financial Analysis, 12, 421-433.

McGoun, E., \& Zielonka, P. (2006). The platonic foundations of finance and the interpretation of finance models. Journal of Behavioral Finance, 7, 43-57.

Miles, I., Barreto, G., Flanagan, K., Green, L., Malik, K., \& Swann, G.M. (2003). Knowing how, knowing whom: A study of the links between Knowledge Intensive Services Sector and the science base. London: Council for Science and Technology, Department of Trade and Industry.

Mobley, M. F., \& Kuniansky, H. (1992). Chief Financial Officers' views of academicians versus practitioners in the field of finance. Financial Practice and Education, 2(1), 67-71.

Mulherin, J. H., Netter, J. M., \& Poulsen, A. B. (2018). Observations on research and publishing from nineteen years as editors of the Journal of Corporate Finance. Journal of Corporate Finance, 49, 120 124.

Netter, J. M., Poulsen, A. B., \& Keiser, W. P. (2018). What does it take? Comparison of research standards for promotion in finance. Journal of Corporate Finance, 49, 379-387.

O'Hara, M. (2016). Something for Nothing: Arbitrage and ethics on Wall Street. New York / London: W.W. Norton \& Company, Inc.

Palea, V. (2017). Whither accounting research? A European view. Critical Perspectives on Accounting, 42, 59-73.

Pavelin, S., \& Porter, L. A. (2008). The corporate social performance content of innovation in the UK. Journal of Business Ethics, 80(4), 711-725.

Pelger, C., \& Grottke, M. (2015). What about the future of the academy? - Some remarks on the looming colonisation of doctoral education. Critical Perspectives on Accounting, 26, 117-129.

Power, M. K., \& Gendron, Y. (2015). Qualitative research in auditing: A methodological roadmap. Auditing: A Journal of Practice \& Theory, 34(2), 147-165.

Prasad, A. (2015). Liminal transgressions, or where should the critical academy go from here? Reimagining the future of doctoral education to engender research sustainability. Critical Perspectives on Accounting, 26, 108-116. 
Raineri, N. (2015). Business doctoral education as a liminal period of transition: Comparing theory and practice. Critical Perspectives on Accounting, 26, 99-107.

Raines, J. P., \& Leathers, C. G. (1994). Financial derivative instruments and social ethics. Journal of Business Ethics, 13, 197-204.

Roberts, R. W. (2018). We can do so much better: Reflections on reading "Signaling Effects of Scholarly Profiles-The Editorial Teams of North American Accounting Association Journals". Critical Perspectives on Accounting, 51, 70-77.

Rooney, D., Mandeville, T., \& Kastelle, T. (2013). Abstract knowledge and reified financial innovation: Building wisdom and ethics into financial innovation networks. Journal of Business Ethics, 118, 447459.

Ryan, L. V., Buchholtz, A. K., \& Kolb, R. W. (2010). New directions in corporate governance and finance: Implications for business ethics research. Business Ethics Quarterly, 20(4), 673-694.

Rynes, S., Bartunek, J., \& Daft, R. L. (2001). Across the great divide: Knowledge creation and transfer between practitioners and academics. Academy of Management Journal, 44, 340-355.

Salmona, S., Kaczynski, D., \& and Smith, T. (2015). Qualitative theory in finance: Theory into practice. Australian Journal of Management, 40, 403-413.

Salterio, S. E. (2018). Signaling effects of scholarly profiles-the editorial teams of North American accounting association journals: A personal perspective. Critical Perspectives on Accounting, 51, 7883.

Santoro, M. A., \& Strauss, R .J. (2012). Wall Street Values: Business Ethics and the Global Financial Crisis. New York: Cambridge University Press.

Shefrin, H., \& Statman, M. (1993). Ethics, fairness and efficiency in financial markets. Financial Analysts Journal, 49(6), 21-29.

Shiller, R. C. (2000). Irrational exuberance. Philosophy and Public Policy Quarterly, 20(1), 18-23.

Shiller, R. C. (2010). How should the financial crisis change the way we teach economics? Journal of Economic Education, 41(4), 403-409.

Siegel, M. (2012). Reviewing less - progression more. Review of Financial Studies, 25(5) 2012, 1331-1338.

Sullivan, J. B. (1993). The impact of auditing research on auditing practice. Auditing: A Journal of Practice and Theory, 12, 1-2.

Swedberg, R. (2011). The economic sociologies of Pierre Bourdieu. Cultural sociology, 5(1), 67-82.

Taleb, N. N. (2007). The black swan: The impact of the highly improbable. New York: Random House.

Trahan, E., \& Gitman, L. (1995). Bridging the theory-practice gap in corporate finance: A survey of chief financial officers. Quarterly Review of Economics and Finance, 35, 73-78.

Triana, P. (2009). Lecturing birds on flying: Can mathematical theories destroy the financial markets? New Jersey: Wiley. 
Tuckett, D. (2009). Addressing the psychology of financial markets. Economics, 3, 1-22.

Tunzelmann, N., \& Mbula, E. K. (2003). Changes in Research Assessment Practices in Other Countries Since 1999. Higher Education Funding Council for England, Bristol.

Veit, E. T., \& Cheney, J. M. (1984). Managing investment portfolios: a survey of mutual funds. Financial Review, 19(4), 321-36.

Vermeulen, F. (2005). On rigor and relevance: fostering dialectic progress in management research. Academy of Management Journal, 48, 978-982.

Vermeulen, F. (2007). 'I shall not remain insignificant': Adding a second loop to matter more. Academy of Management Journal, 50(4), 754-761.

Watermeyer, R., \& Olssen, M. (2016). 'Excellence' and Exclusion: The Individual Costs of Institutional Competitiveness. Minerva, 54(2), 201-218.

Weaver, G. R. (2011). Corporate Governance and Finance: How did they get this way, where are they going in Comments on BEQ's Twentieth Anniversary Forum on New Directions for Business Ethics Research. Business Ethics Quarterly, 21(1), 157-187.

Walker, J. T., Salter, A., \& Salandra, R. (2015). Initial Findings from the Survey of UK Business Academics 2015, Report to Survey Participants.

West, J. (2015). Quantitative method in finance: From detachment to ethical engagement. Journal of Business Ethics, 129(3), 599-611.

Whitley, R. (1986). The transformation of business finance into financial economics: the roles of academic expansion and changes in US capital markets. Accounting, Organization and Society, 11(2), 171-192.

Willmott, H. (1995). Managing the academics: commodification and control in the development of university education in the UK. Human Relations, 48, 993-1027.

Willmott, H. (2011a). Journal list fetishism and the perversion of scholarship: reactivity and the ABS list. Organization, 18, 429-442.

Willmott, H. (2011b). Listing perilously. Organization, 18(4), 447-448.

Young, H. P. (1993). The evolution of conventions, Econometrica, 61(1), 57-84.

Zingales, L. (2015). Presidential Address: Does finance benefit society? Journal of Finance, 70(4), $1327-1363$. 
Table 1: Percentage of Papers submitted to the RAE2008 and REF2014 by University Ranking and ABS Journal Rating List

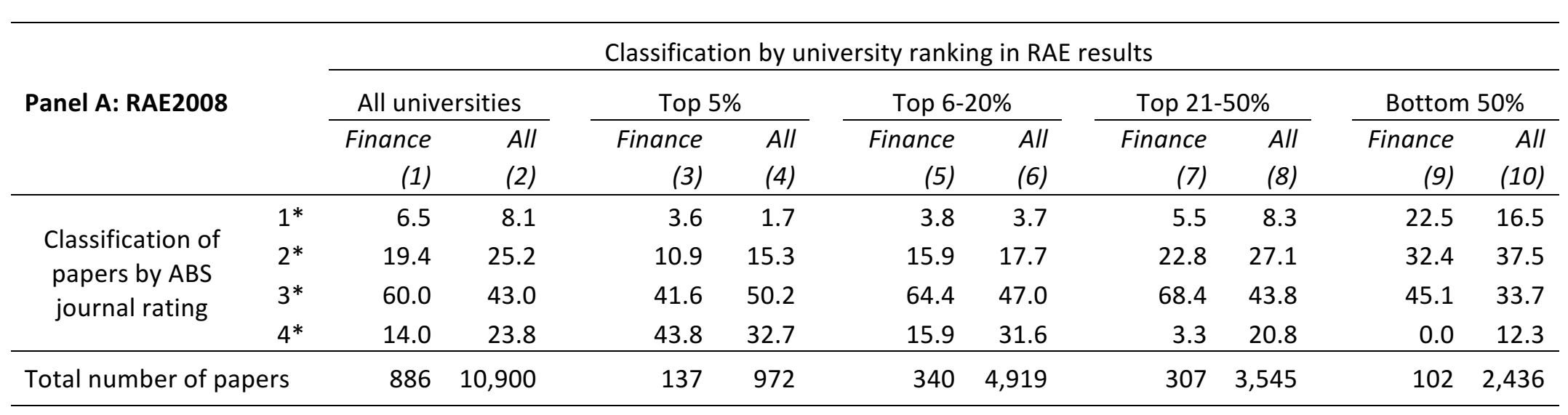

Classification by university ranking in REF results

\begin{tabular}{|c|c|c|c|c|c|c|c|c|c|c|c|}
\hline \multirow[t]{3}{*}{ Panel B: REF2014 } & & \multicolumn{2}{|c|}{ All universities } & \multicolumn{2}{|c|}{ Top 5\% } & \multicolumn{2}{|c|}{ Top 6-20\% } & \multicolumn{2}{|c|}{ Top 21-50\% } & \multicolumn{2}{|c|}{ Bottom $50 \%$} \\
\hline & & Finance & All & Finance & All & Finance & All & Finance & All & Finance & All \\
\hline & & (1) & (2) & (3) & (4) & (5) & (6) & (7) & (8) & (9) & (10) \\
\hline \multirow{4}{*}{$\begin{array}{l}\text { Classification of } \\
\text { papers by ABS } \\
\text { journal rating }\end{array}$} & $1^{*}$ & 2.2 & 1.9 & 1.4 & 0.9 & 0.7 & 0.9 & 0.9 & 0.9 & 3.9 & 3.1 \\
\hline & $2^{*}$ & 8.8 & 11.6 & 4.2 & 3.3 & 7.6 & 5.2 & 8.2 & 12.0 & 11.0 & 15.7 \\
\hline & $3^{*}$ & 63.5 & 53.8 & 11.2 & 25.4 & 72.0 & 51.9 & 82.8 & 61.0 & 64.8 & 55.3 \\
\hline & $4^{*}$ & 25.6 & 32.7 & 83.2 & 70.4 & 19.6 & 41.9 & 8.2 & 26.2 & 20.3 & 25.9 \\
\hline \multicolumn{2}{|c|}{ Total number of papers } & 1,142 & 9,588 & 143 & 638 & 275 & 2,220 & 232 & 2,187 & 492 & 4,543 \\
\hline
\end{tabular}

Source: RAE2008 and REF2014 results are classified using the ABS2010 journal classification. RAE2008 is composed of the Accounting and Finance and Business and Management units of assessment which were merged for REF2014. 
Table 2: Summary Statistics on the Volume of Research Published in Leading Finance Journals

\begin{tabular}{|c|c|c|c|c|c|c|c|c|c|c|c|c|c|}
\hline \multirow{2}{*}{$\begin{array}{l}\text { Panel A } \\
\text { Journals }\end{array}$} & \multicolumn{6}{|c|}{ Number of Studies } & \multirow{2}{*}{$\begin{array}{l}\text { Panel B } \\
\text { Journals }\end{array}$} & \multicolumn{6}{|c|}{ Average Number of Pages per Study } \\
\hline & $\begin{array}{l}\text { All } \\
(1)\end{array}$ & $\begin{array}{c}1970 \text { 's } \\
\text { (2) }\end{array}$ & $\begin{array}{c}1980 \text { 's } \\
\text { (3) }\end{array}$ & $\begin{array}{c}1990 \text { 's } \\
\text { (4) }\end{array}$ & $\begin{array}{c}2000 \text { 's } \\
\text { (5) }\end{array}$ & $\begin{array}{c}2010 \text { 's } \\
(6)\end{array}$ & & $\begin{array}{l}\text { All } \\
\text { (1) }\end{array}$ & $\begin{array}{c}1970 \text { 's } \\
\text { (2) }\end{array}$ & $\begin{array}{c}1980 \text { 's } \\
\text { (3) }\end{array}$ & $\begin{array}{c}1990 \text { 's } \\
\text { (4) }\end{array}$ & $\begin{array}{c}2000 \text { 's } \\
\text { (5) }\end{array}$ & $\begin{array}{c}2010 \text { 's } \\
(6)\end{array}$ \\
\hline$J F$ & 1784 & 288 & 372 & 358 & 498 & 268 & $J F$ & 24.92 & 12.88 & 14.62 & 23.89 & 33.81 & 37.04 \\
\hline$J F E$ & 1263 & 69 & 153 & 210 & 366 & 465 & $J F E$ & 25.30 & 22.72 & 23.76 & 28.22 & 30.09 & 21.10 \\
\hline RFS & 698 & - & 18 & 144 & 242 & 294 & RFS & 34.94 & - & 24.11 & 29.83 & 33.89 & 38.97 \\
\hline$J F Q A$ & 832 & 180 & 206 & 160 & 168 & 118 & $J F Q A$ & 19.36 & 13.86 & 15.54 & 18.56 & 25.07 & 27.41 \\
\hline RoF & 170 & - & - & 13 & 85 & 72 & RoF & 34.13 & - & - & 25.69 & 32.15 & 37.99 \\
\hline All & 4747 & 537 & 749 & 885 & 1359 & 1217 & All & 25.85 & 14.47 & 16.97 & 24.95 & 31.64 & 30.54 \\
\hline
\end{tabular}

\begin{tabular}{|c|c|c|c|c|c|c|c|c|c|c|c|c|c|}
\hline \multirow{2}{*}{$\begin{array}{l}\text { Panel C } \\
\text { Journals }\end{array}$} & \multicolumn{6}{|c|}{ Average Number of Studies per Issue } & \multirow{2}{*}{$\begin{array}{l}\text { Panel D } \\
\text { Journals }\end{array}$} & \multicolumn{6}{|c|}{ Average Number of Issues per Year } \\
\hline & $\begin{array}{l}\text { All } \\
(1)\end{array}$ & $\begin{array}{c}1970 \text { 's } \\
(2)\end{array}$ & $\begin{array}{c}1980 \text { 's } \\
\text { (3) }\end{array}$ & $\begin{array}{c}\text { 1990's } \\
\text { (4) }\end{array}$ & $\begin{array}{c}2000 \text { 's } \\
\text { (5) }\end{array}$ & $\begin{array}{c}2010 \text { 's } \\
(6)\end{array}$ & & $\begin{array}{l}\text { All } \\
(1)\end{array}$ & $\begin{array}{c}\text { 1970's } \\
\text { (2) }\end{array}$ & $\begin{array}{c}\text { 1980's } \\
\text { (3) }\end{array}$ & $\begin{array}{c}\text { 1990's } \\
\text { (4) }\end{array}$ & $\begin{array}{c}2000 \text { 's } \\
\text { (5) }\end{array}$ & $\begin{array}{c}2010 \text { 's } \\
(6)\end{array}$ \\
\hline$J F$ & 14.13 & 19.87 & 14.88 & 13.81 & 13.83 & 10.72 & $J F$ & 5.38 & 5.00 & 5.00 & 5.20 & 6.00 & 6.00 \\
\hline$J F E$ & 7.20 & 5.14 & 7.29 & 5.41 & 6.42 & 10.33 & $J F E$ & 8.02 & 4.50 & 4.60 & 7.90 & 11.70 & 12.00 \\
\hline RFS & 8.70 & - & 4.50 & 0.20 & 10.83 & 8.65 & RFS & 6.00 & - & 4.00 & 4.10 & 5.30 & 12.00 \\
\hline$J F Q A$ & 9.14 & 11.25 & 9.36 & 8.00 & 8.40 & 9.08 & $J F Q A$ & 4.56 & 5.10 & 4.30 & 4.00 & 4.20 & 5.80 \\
\hline RoF & 5.31 & - & - & 4.33 & 4.72 & 6.55 & $R o F$ & 3.78 & - & - & 3.00 & 3.50 & 4.80 \\
\hline All & 9.41 & 12.22 & 10.40 & 8.21 & 8.87 & 9.51 & All & 5.72 & 4.92 & 4.59 & 5.14 & 6.14 & 8.12 \\
\hline
\end{tabular}

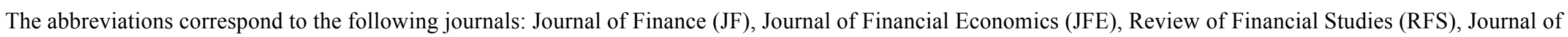
Financial and Quantitative Analysis (JFQA), and the Review of Finance (RoF) 
Table 3: Proportion of Articles in Leading Finance Journals using Quantitative Empirical Analyses

\begin{tabular}{|c|c|c|c|c|c|c|c|c|c|c|c|c|}
\hline \multirow[b]{3}{*}{ Journals } & \multicolumn{12}{|c|}{ Papers using Quantitative Empirical Analyses } \\
\hline & \multicolumn{2}{|c|}{ All } & \multicolumn{2}{|c|}{ 1970's } & \multicolumn{2}{|c|}{ 1980's } & \multicolumn{2}{|c|}{ 1990's } & \multicolumn{2}{|c|}{ 2000's } & \multicolumn{2}{|c|}{ 2010's } \\
\hline & $(1)$ & $(2)$ & (3) & $(4)$ & $(5)$ & (6) & (7) & $(8)$ & (9) & $(10)$ & $(11)$ & $(12)$ \\
\hline$J F$ & 1279 & $72 \%$ & 168 & $58 \%$ & 219 & $59 \%$ & 268 & $75 \%$ & 406 & $82 \%$ & 218 & $81 \%$ \\
\hline$J F E$ & 1060 & $84 \%$ & 23 & $33 \%$ & 116 & $76 \%$ & 191 & $91 \%$ & 318 & $87 \%$ & 412 & $89 \%$ \\
\hline RFS & 501 & $72 \%$ & - & - & 8 & $44 \%$ & 75 & $52 \%$ & 178 & $74 \%$ & 240 & $82 \%$ \\
\hline$J F Q A$ & 507 & $61 \%$ & 94 & $52 \%$ & 111 & $54 \%$ & 95 & $59 \%$ & 121 & $72 \%$ & 86 & $73 \%$ \\
\hline$R o F$ & 127 & $75 \%$ & - & - & - & - & 4 & $31 \%$ & 60 & $71 \%$ & 63 & $88 \%$ \\
\hline All & 3474 & $73 \%$ & 285 & $53 \%$ & 454 & $61 \%$ & 633 & $72 \%$ & 1083 & $80 \%$ & 1019 & $84 \%$ \\
\hline
\end{tabular}

The abbreviations correspond to the following journals: Journal of Finance (JF), Journal of Financial Economics (JFE), Review of Financial Studies (RFS), Journal of Financial and Quantitative Analysis (JFQA), and the Review of Finance (RoF). In this table, 'empirical' includes both the analysis of secondary datasets but could also involve analysis of the results from surveys or case studies; however, the former type of empirical work is vastly dominant. 
Table 4: Data Sources Used in Empirical Studies Published in Leading Finance Journals

\begin{tabular}{|c|c|c|c|c|c|c|c|c|c|c|c|c|}
\hline \multirow{3}{*}{$\begin{array}{l}\text { Panel A } \\
\text { Journals }\end{array}$} & \multicolumn{12}{|c|}{ Studies using standard data sources only } \\
\hline & \multicolumn{2}{|c|}{ All } & \multicolumn{2}{|c|}{ 1970's } & \multicolumn{2}{|c|}{ 1980's } & \multicolumn{2}{|c|}{ 1990's } & \multicolumn{2}{|c|}{ 2000's } & \multicolumn{2}{|c|}{ 2010's } \\
\hline & (1) & (2) & (3) & $(4)$ & $(5)$ & (6) & (7) & $(8)$ & (9) & $(10)$ & $(11)$ & $(12)$ \\
\hline$J F$ & 399 & $31 \%$ & 23 & $14 \%$ & 60 & $27 \%$ & 78 & $29 \%$ & 173 & $43 \%$ & 65 & $30 \%$ \\
\hline$J F E$ & 300 & $28 \%$ & 1 & $4 \%$ & 30 & $26 \%$ & 48 & $25 \%$ & 115 & $36 \%$ & 106 & $26 \%$ \\
\hline RFS & 163 & $33 \%$ & & & 2 & $25 \%$ & 16 & $21 \%$ & 72 & $40 \%$ & 73 & $30 \%$ \\
\hline$J F Q A$ & 198 & $39 \%$ & 38 & $40 \%$ & 43 & $39 \%$ & 34 & $36 \%$ & 44 & $36 \%$ & 39 & $45 \%$ \\
\hline RoF & 35 & $28 \%$ & & & & & 1 & $25 \%$ & 14 & $23 \%$ & 20 & $32 \%$ \\
\hline All & 1095 & $32 \%$ & 62 & $22 \%$ & 135 & $30 \%$ & 177 & $28 \%$ & 418 & $39 \%$ & 303 & $30 \%$ \\
\hline \multirow[t]{2}{*}{ Panel B } & \multicolumn{12}{|c|}{ Studies using non-standard data sources only } \\
\hline & \multicolumn{2}{|c|}{ All } & \multicolumn{2}{|c|}{ 1970's } & \multicolumn{2}{|c|}{ 1980's } & \multicolumn{2}{|c|}{ 1990's } & \multicolumn{2}{|c|}{ 2000's } & \multicolumn{2}{|c|}{ 2010's } \\
\hline Journals & $(1)$ & $(2)$ & (3) & (4) & (5) & $(6)$ & (7) & (8) & (9) & (10) & (11) & $(12)$ \\
\hline$J F$ & 574 & $45 \%$ & 124 & $74 \%$ & 118 & $54 \%$ & 100 & $37 \%$ & 148 & $36 \%$ & 84 & $39 \%$ \\
\hline$J F E$ & 280 & $26 \%$ & 7 & $30 \%$ & 27 & $23 \%$ & 60 & $31 \%$ & 80 & $25 \%$ & 106 & $26 \%$ \\
\hline RFS & 162 & $32 \%$ & & & 2 & $25 \%$ & 27 & $36 \%$ & 49 & $28 \%$ & 84 & $35 \%$ \\
\hline$J F Q A$ & 185 & $36 \%$ & 50 & $53 \%$ & 50 & $45 \%$ & 30 & $32 \%$ & 33 & $27 \%$ & 21 & $24 \%$ \\
\hline RoF & 70 & $55 \%$ & & & & & 3 & $75 \%$ & 37 & $62 \%$ & 30 & $48 \%$ \\
\hline All & 1271 & $37 \%$ & 181 & $64 \%$ & 197 & $43 \%$ & 221 & $35 \%$ & 347 & $32 \%$ & 325 & $32 \%$ \\
\hline \multirow[t]{2}{*}{ Panel C } & \multicolumn{12}{|c|}{ Studies using standard and non-standard data sources } \\
\hline & \multicolumn{2}{|c|}{ All } & & & \multicolumn{2}{|c|}{ 1980's } & \multicolumn{2}{|c|}{ 1990's } & \multicolumn{2}{|c|}{ 2000's } & \multicolumn{2}{|c|}{ 2010's } \\
\hline Journals & (1) & $(2)$ & (3) & $(4)$ & $(5)$ & (6) & (7) & (8) & (9) & $(10)$ & (11) & $(12)$ \\
\hline JF & 306 & $24 \%$ & 21 & $13 \%$ & 41 & $19 \%$ & 90 & $34 \%$ & 85 & $21 \%$ & 69 & $32 \%$ \\
\hline$J F E$ & 480 & $45 \%$ & 15 & $65 \%$ & 59 & $51 \%$ & 83 & $43 \%$ & 123 & $39 \%$ & 200 & $49 \%$ \\
\hline$R F S$ & 176 & $35 \%$ & & & 4 & $50 \%$ & 32 & $43 \%$ & 57 & $32 \%$ & 83 & $35 \%$ \\
\hline$J F Q A$ & 124 & $24 \%$ & 6 & $6 \%$ & 18 & $16 \%$ & 30 & $32 \%$ & 44 & $36 \%$ & 26 & $30 \%$ \\
\hline RoF & 22 & $17 \%$ & & & & & 0 & $0 \%$ & 9 & $15 \%$ & 13 & $21 \%$ \\
\hline All & 1108 & $32 \%$ & 42 & $15 \%$ & 122 & $27 \%$ & 235 & $37 \%$ & 318 & $29 \%$ & 391 & $38 \%$ \\
\hline
\end{tabular}

Standard data sources are defined as: CRSP, Compustat, CDA/Spectrum/Thomson Holdings data, SEC/Edgar, Lexis/Nexis, IBES, Bloomberg, Datastream, Worldscope, Fama-French database, NYSE / AMEX / NASDAQ / S\&P500 / Dow Jones Universe, Execucomp, SDC, TAQ, Lipper TASS. The abbreviations correspond to the following journals: Journal of Finance (JF), Journal of Financial Economics (JFE), Review of Financial Studies (RFS), Journal of Financial and Quantitative Analysis (JFQA), and the Review of Finance (RoF) 
Table 5: Location of Authors of Publications in Leading Finance Journals

\begin{tabular}{|c|c|c|c|c|c|c|c|c|c|c|c|c|}
\hline \multirow{3}{*}{$\begin{array}{l}\text { Panel A } \\
\text { Journals }\end{array}$} & \multicolumn{12}{|c|}{ Papers with at least one author from a US institution } \\
\hline & \multicolumn{2}{|c|}{ All } & \multicolumn{2}{|c|}{ 1970's } & \multicolumn{2}{|c|}{ 1980's } & \multicolumn{2}{|c|}{ 1990's } & \multicolumn{2}{|c|}{ 2000's } & \multicolumn{2}{|c|}{ 2010's } \\
\hline & (1) & (2) & (3) & (4) & (5) & (6) & (7) & (8) & (9) & $(10)$ & (11) & (12) \\
\hline JF & 1598 & $90 \%$ & 263 & $91 \%$ & 333 & $90 \%$ & 338 & $94 \%$ & 437 & $88 \%$ & 227 & $85 \%$ \\
\hline$J F E$ & 1116 & $88 \%$ & 65 & $94 \%$ & 147 & $96 \%$ & 201 & $96 \%$ & 318 & $87 \%$ & 385 & $83 \%$ \\
\hline RFS & 598 & $86 \%$ & - & - & 18 & $100 \%$ & 122 & $85 \%$ & 208 & $86 \%$ & 250 & $85 \%$ \\
\hline$J F Q A$ & 697 & $84 \%$ & 162 & $90 \%$ & 186 & $90 \%$ & 137 & $86 \%$ & 129 & $77 \%$ & 83 & $70 \%$ \\
\hline RoF & 80 & $47 \%$ & - & - & - & - & 8 & $62 \%$ & 38 & $45 \%$ & 34 & $47 \%$ \\
\hline All & 4089 & $86 \%$ & 490 & $91 \%$ & 684 & $91 \%$ & 806 & $91 \%$ & 1130 & $83 \%$ & 979 & $80 \%$ \\
\hline \multicolumn{13}{|c|}{ Papers with all authors from US institutions } \\
\hline & \multicolumn{2}{|c|}{ All } & \multicolumn{2}{|c|}{ 1970's } & \multicolumn{2}{|c|}{ 1980's } & \multicolumn{2}{|c|}{ 1990's } & \multicolumn{2}{|c|}{ 2000's } & \multicolumn{2}{|c|}{ 2010's } \\
\hline Journals & $(1)$ & (2) & (3) & (4) & $(5)$ & (6) & (7) & $(8)$ & (9) & $(10)$ & (11) & (12) \\
\hline$J F$ & 1363 & $76 \%$ & 244 & $85 \%$ & 298 & $80 \%$ & 304 & $85 \%$ & 358 & $72 \%$ & 159 & $59 \%$ \\
\hline$J F E$ & 887 & $70 \%$ & 63 & $91 \%$ & 133 & $87 \%$ & 183 & $87 \%$ & 247 & $67 \%$ & 261 & $56 \%$ \\
\hline RFS & 443 & $63 \%$ & - & - & 17 & $94 \%$ & 109 & $76 \%$ & 158 & $65 \%$ & 159 & $54 \%$ \\
\hline$J F Q A$ & 593 & $71 \%$ & 155 & $86 \%$ & 173 & $84 \%$ & 118 & $74 \%$ & 94 & $56 \%$ & 53 & $45 \%$ \\
\hline RoF & 46 & $27 \%$ & - & - & - & - & 3 & $23 \%$ & 23 & $27 \%$ & 20 & $28 \%$ \\
\hline All & 3332 & $70 \%$ & 462 & $86 \%$ & 621 & $83 \%$ & 717 & $81 \%$ & 880 & $65 \%$ & 652 & $54 \%$ \\
\hline
\end{tabular}

The abbreviations correspond to the following journals: Journal of Finance (JF), Journal of Financial Economics (JFE), Review of Financial Studies (RFS), Journal of Financial and Quantitative Analysis (JFQA), and the Review of Finance (RoF) 
Table 6: Country Coverage of Data Employed in Empirical Studies Published in Leading Finance Journals

\begin{tabular}{|c|c|c|c|c|c|c|c|c|c|c|c|c|}
\hline \multirow{3}{*}{$\begin{array}{l}\text { Panel A } \\
\text { Journals }\end{array}$} & \multicolumn{12}{|c|}{ Studies using non US data only } \\
\hline & \multicolumn{2}{|c|}{ All } & \multicolumn{2}{|c|}{ 1970's } & \multicolumn{2}{|c|}{1980 's } & \multicolumn{2}{|c|}{ 1990's } & \multicolumn{2}{|c|}{ 2000's } & \multicolumn{2}{|c|}{ 2010's } \\
\hline & (1) & (2) & (3) & (4) & (5) & (6) & (7) & (8) & (9) & (10) & (11) & (12) \\
\hline$J F$ & 59 & $5 \%$ & 4 & $2 \%$ & 9 & $4 \%$ & 11 & $4 \%$ & 23 & $6 \%$ & 12 & $6 \%$ \\
\hline$J F E$ & 38 & $4 \%$ & 0 & $0 \%$ & 2 & $2 \%$ & 8 & $4 \%$ & 16 & $5 \%$ & 12 & $3 \%$ \\
\hline RFS & 24 & $5 \%$ & - & - & 0 & $0 \%$ & 2 & $3 \%$ & 8 & $4 \%$ & 14 & $6 \%$ \\
\hline$J F Q A$ & 18 & $4 \%$ & 1 & $1 \%$ & 3 & $3 \%$ & 4 & $4 \%$ & 6 & $5 \%$ & 4 & $5 \%$ \\
\hline RoF & 23 & $19 \%$ & - & - & - & - & 1 & $25 \%$ & 13 & $23 \%$ & 9 & $14 \%$ \\
\hline All & 162 & $5 \%$ & 5 & $2 \%$ & 14 & $3 \%$ & 26 & $4 \%$ & 66 & $6 \%$ & 51 & $5 \%$ \\
\hline \multirow{3}{*}{$\begin{array}{l}\text { Panel B } \\
\text { Journals }\end{array}$} & \multicolumn{12}{|c|}{ Studies using US data only } \\
\hline & \multicolumn{2}{|c|}{ All } & \multicolumn{2}{|c|}{ 1970's } & \multicolumn{2}{|c|}{ 1980's } & \multicolumn{2}{|c|}{ 1990's } & \multicolumn{2}{|c|}{ 2000's } & \multicolumn{2}{|c|}{ 2010's } \\
\hline & (1) & $(2)$ & (3) & (4) & (5) & (6) & (7) & (8) & (9) & (10) & $(11)$ & (12) \\
\hline$J F$ & 1080 & $89 \%$ & 152 & $93 \%$ & 192 & $89 \%$ & 232 & $89 \%$ & 336 & $88 \%$ & 168 & $88 \%$ \\
\hline$J F E$ & 955 & $91 \%$ & 22 & $96 \%$ & 111 & $97 \%$ & 173 & $91 \%$ & 272 & $88 \%$ & 377 & $92 \%$ \\
\hline RFS & 434 & $88 \%$ & - & - & 8 & $100 \%$ & 60 & $80 \%$ & 157 & $88 \%$ & 212 & $90 \%$ \\
\hline$J F Q A$ & 454 & $91 \%$ & 87 & $94 \%$ & 102 & $94 \%$ & 83 & $91 \%$ & 106 & $88 \%$ & 76 & $90 \%$ \\
\hline RoF & 82 & $66 \%$ & - & - & - & - & 2 & $50 \%$ & 31 & $54 \%$ & 49 & $78 \%$ \\
\hline All & 3008 & $89 \%$ & 261 & $93 \%$ & 413 & $92 \%$ & 550 & $88 \%$ & 902 & $86 \%$ & 882 & $90 \%$ \\
\hline \multirow{3}{*}{$\begin{array}{l}\text { Panel C } \\
\text { Journals }\end{array}$} & \multicolumn{12}{|c|}{ Studies using multiple country data including US } \\
\hline & \multicolumn{2}{|c|}{ All } & \multicolumn{2}{|c|}{ 1970's } & \multicolumn{2}{|c|}{ 1980's } & \multicolumn{2}{|c|}{ 1990's } & \multicolumn{2}{|c|}{ 2000's } & \multicolumn{2}{|c|}{ 2010's } \\
\hline & (1) & $(2)$ & (3) & $(4)$ & (5) & (6) & (7) & (8) & (9) & (10) & (11) & (12) \\
\hline JF & 65 & $5 \%$ & 7 & $4 \%$ & 14 & $7 \%$ & 17 & $6 \%$ & 20 & $5 \%$ & 7 & $4 \%$ \\
\hline$J F E$ & 51 & $5 \%$ & 1 & $4 \%$ & 1 & $1 \%$ & 8 & $4 \%$ & 21 & $7 \%$ & 20 & $5 \%$ \\
\hline$R F S$ & 31 & $6 \%$ & - & - & 0 & $0 \%$ & 13 & $17 \%$ & 10 & $6 \%$ & 8 & $3 \%$ \\
\hline$J F Q A$ & 23 & $5 \%$ & 5 & $5 \%$ & 4 & $4 \%$ & 4 & $4 \%$ & 8 & $7 \%$ & 2 & $2 \%$ \\
\hline RoF & 13 & $10 \%$ & - & - & - & - & 1 & $25 \%$ & 9 & $16 \%$ & 3 & $5 \%$ \\
\hline All & 183 & $5 \%$ & 13 & $5 \%$ & 19 & $4 \%$ & 43 & $7 \%$ & 68 & $7 \%$ & 40 & $4 \%$ \\
\hline \multirow{3}{*}{$\begin{array}{l}\text { Panel D } \\
\text { Journals }\end{array}$} & & & & Stuc & sing & Itiple c & ry da & excluc & US & & & \\
\hline & & & & O's & & O's & & O's & & & & O's \\
\hline & (1) & (2) & (3) & (4) & (5) & (6) & (7) & (8) & (9) & (10) & (11) & (12) \\
\hline$J F$ & 7 & $1 \%$ & 1 & $1 \%$ & 0 & $0 \%$ & 2 & $1 \%$ & 1 & $0 \%$ & 3 & $2 \%$ \\
\hline$J F E$ & 3 & $0 \%$ & 0 & $0 \%$ & 1 & $1 \%$ & 1 & $1 \%$ & 1 & $0 \%$ & 0 & $0 \%$ \\
\hline RFS & 5 & $1 \%$ & - & - & 0 & $0 \%$ & 0 & $0 \%$ & 3 & $2 \%$ & 2 & $1 \%$ \\
\hline$J F Q A$ & 2 & $0 \%$ & 0 & $0 \%$ & 0 & $0 \%$ & 0 & $0 \%$ & 0 & $0 \%$ & 2 & $2 \%$ \\
\hline RoF & 6 & $5 \%$ & - & - & - & - & 0 & $0 \%$ & 4 & $7 \%$ & 2 & $3 \%$ \\
\hline All & 23 & $1 \%$ & 1 & $0 \%$ & 1 & $0 \%$ & 3 & $0 \%$ & 9 & $1 \%$ & 9 & $1 \%$ \\
\hline
\end{tabular}

The abbreviations correspond to the following journals: Journal of Finance (JF), Journal of Financial Economics (JFE), Review of Financial Studies (RFS), Journal of Financial and Quantitative Analysis (JFQA), and the Review of Finance (RoF) 
Table 7: Data Coverage by Author Location

\begin{tabular}{|c|c|c|c|c|c|}
\hline & & \multicolumn{4}{|c|}{ Data Coverage } \\
\hline & & US only & non-US & multi excl. US & multi incl. US \\
\hline & & (1) & (2) & (3) & (4) \\
\hline Panel A: & All Years & $70.8 \%$ & $16.2 \%$ & $2.3 \%$ & $10.7 \%$ \\
\hline \multirow[t]{5}{*}{ No US authors } & $1970 s$ & $82.4 \%$ & $11.8 \%$ & $0.0 \%$ & $5.9 \%$ \\
\hline & $1980 s$ & $67.6 \%$ & $26.5 \%$ & $0.0 \%$ & $5.9 \%$ \\
\hline & $1990 \mathrm{~s}$ & $60.5 \%$ & $18.4 \%$ & $0.0 \%$ & $21.1 \%$ \\
\hline & $2000 \mathrm{~s}$ & $66.3 \%$ & $18.1 \%$ & $3.1 \%$ & $12.5 \%$ \\
\hline & $2010 s$ & $76.4 \%$ & $12.6 \%$ & $2.7 \%$ & $8.2 \%$ \\
\hline Panel B: & All Years & $93.8 \%$ & $1.8 \%$ & $0.3 \%$ & $4.2 \%$ \\
\hline \multirow[t]{5}{*}{ All US authors } & $1970 s$ & $94.4 \%$ & $1.2 \%$ & $0.4 \%$ & $4.0 \%$ \\
\hline & $1980 \mathrm{~s}$ & $96.0 \%$ & $0.8 \%$ & $0.0 \%$ & $3.2 \%$ \\
\hline & $1990 s$ & $91.5 \%$ & $1.9 \%$ & $0.6 \%$ & $6.0 \%$ \\
\hline & $2000 \mathrm{~s}$ & $93.4 \%$ & $2.0 \%$ & $0.3 \%$ & $4.3 \%$ \\
\hline & $2010 s$ & $94.8 \%$ & $2.2 \%$ & $0.0 \%$ & $3.0 \%$ \\
\hline Panel C: & All Years & $91.8 \%$ & $3.1 \%$ & $0.4 \%$ & $4.7 \%$ \\
\hline \multirow[t]{5}{*}{ At least one US author } & $1970 s$ & $93.9 \%$ & $1.1 \%$ & $0.4 \%$ & $4.6 \%$ \\
\hline & $1980 \mathrm{~s}$ & $94.4 \%$ & $1.2 \%$ & $0.2 \%$ & $4.1 \%$ \\
\hline & $1990 \mathrm{~s}$ & $90.2 \%$ & $3.3 \%$ & $0.5 \%$ & $6.0 \%$ \\
\hline & $2000 \mathrm{~s}$ & $89.9 \%$ & $4.2 \%$ & $0.5 \%$ & $5.4 \%$ \\
\hline & $2010 \mathrm{~s}$ & $92.9 \%$ & $3.5 \%$ & $0.5 \%$ & $3.1 \%$ \\
\hline
\end{tabular}

Due to rounding, figures in rows may not sum up to $100 \%$. 